www.nature.com/pj

\title{
Synthesis and structure determination of helical polymers
}

\author{
Eiji Yashima
}

During the last decade, remarkable progress in developing synthetic helical polymers with a controlled helical sense has been achieved. However, the exact helical structures of most of the already prepared synthetic helical polymers remain unsolved. In this review, the recent progress in the synthesis of helical polymers and their structural determination, including helical pitch and handedness based on X-ray diffraction and spectroscopic measurements, together with high-resolution atomic force microscopy, is described.

Polymer Journal (2010) 42, 3-16; doi:10.1038/pj.2009.314

Keywords: atomic force microscopy; circular dichroism; helical polymer; helical structure; X-ray diffraction

The helix is a unique structure as observed in nature from microscopic to macroscopic levels and is inherently chiral. Inspired by biological helices, such as DNA and proteins, chemists have been challenged to synthesize helical polymers with a controlled helical sense that aims not only to mimic biological helical structures but also to develop chiral materials for the separation of enantiomers and asymmetric catalysis. $^{1-12}$ The history of synthetic helical polymers with optical activity extends back to the 1960 s when Pino and Lorenzi ${ }^{13}$ investigated the structural and chiroptical properties of isotactic vinyl polymers prepared by the polymerization of $\alpha$-olefins bearing optically active substituents. Although helical polyolefins are totally dynamic in nature and consist of short helical segments separated by frequently occurring helical reversals among disordered, random coil conformations, ${ }^{14}$ this study was significant in the field of synthetic helical polymers, from which a number of helical polymers have been synthesized.

On the basis of the pioneering studies by Nolte et al., ${ }^{15}$ Okamoto et al. ${ }^{16}$ and Green et al., ${ }^{17}$ the existing synthetic helical polymers that exhibit an optical activity solely because of their macromolecular helicity can be classified into two categories with respect to their helix inversion barriers, that is, static and dynamic helical polymers (Figure 1). ${ }^{9} 12$ Optically active helical polymers, such as poly(triphenylmethyl methacrylate) (1), ${ }^{16}$ poly(t-butyl isocyanide) $(2)^{15}$ and polychloral (3), ${ }^{18}$ have a sufficiently high helix inversion barrier and belong to the family of static helical polymers. Therefore, these helical polymers with either a right- or left-handed helix can be prepared by the helix-sense-selective polymerization of the corresponding achiral monomers using chiral catalysts or initiators under kinetic control. On the other hand, dynamic helical polymers, such as polyisocyanates $(\mathbf{8})^{17}$ and polysilanes $(9),{ }^{19}$ possess a very low helix inversion barrier.
As a consequence, they consist of interconvertible right- and lefthanded helical segments separated by rarely occurring helical reversals, as demonstrated by Green et al., ${ }^{6,20,21}$ so that a preferred-handed helical conformation can be induced in the presence of a small amount of chiral residues at the pendant ${ }^{6}$ or terminal ends ${ }^{22,23}$ or a noncovalently interacting stimulant, ${ }^{24}$ with their helical senses being determined under thermodynamic control. Either static or dynamic helical polymers with an excess one-handedness, such as poly(quinoxaline-2,3-diyl)s (4), ${ }^{25,26}$ polyguanidines (5), ${ }^{27,28}$ poly(phenyl isocyanide)s $(6)^{29,30}$ and polyacetylenes $(7),{ }^{8-12,31-34}$ have also been prepared by the polymerization of analogous monomers bearing different chiral or achiral substituents, that is, the boundary between static and dynamic helical conformations is totally dependent on the helix inversion barrier. In addition, the helical conformations of dynamic helical polymers can be locked, resulting in static helical polymers as demonstrated by the memory effect of induced helical poly(phenylacetylene)s (7) ${ }^{35}$ and poly(4-carboxyphenyl isocyanide) (6: $\mathrm{R}=\mathrm{COOH}) .{ }^{30}$ The details of their pioneering studies have been thoroughly reviewed elsewhere. ${ }^{1-12,25,31,34}$

Although various helical polymers have been synthesized, particularly in the last decade, their exact helical structures, including helical pitch and helical sense (right- or left-handed helix), remain unsolved. The preferred-handed helix formation of most synthetic helical polymers has usually been based on circular dichroism (CD) and/or optical rotation measurements, which, however, may not be straightforward for proposing an unambiguous helical structure. X-ray diffraction (XRD) is among the most convenient techniques for elucidating the structures of helical polymers as clearly demonstrated for biological polymers, such as polypeptides ${ }^{36}$ and DNA. ${ }^{37}$ In fact, on the basis of the XRD measurements of oriented films or fibers derived 
from liquid crystalline (LC) helical polyisocyanates such as poly (n-butyl isocyanate) (10), ${ }^{38}$ and polysilanes, for instance, poly (di- $n$-pentylsilane) $(\mathbf{1 1})^{39}$ and poly $(n$-decyl- $(S)-2$-methylbutylsilane) $(12),{ }^{40}$ their helical structures were elucidated to be the $8 / 3$ helix and $7 / 3$ helix, respectively (Chart 1 ). However, owing to the limited number of diffractions and difficulty in obtaining crystalline samples from most synthetic helical polymers, the XRD method seems to be laborious and cannot provide important structural information, in particular, on the helical sense.

The structural elucidation of helical polymers is required for understanding the mechanism of helix formation and the relationships between their helical structures and functions, and also to develop novel helical polymers with new functions. However, recent significant developments in microscopic instruments such as scanning probe microscopy, ${ }^{41,42}$ coupled with precise polymerization techniques, have made it possible to directly observe the helical structures of certain helical polymers, including helical pitch and handedness, which provides more detailed structural information for understanding the principles underlying the generation of helical conformations. ${ }^{43}$

In this review, the recent progress in the synthesis of helical polymers and their structural determination by means of $\mathrm{CD}$ and vibrational CD (VCD) spectroscopies, single-crystal X-ray analysis of uniform oligomers and the XRD of LC helical polymers, together with the direct observation of helical structures by high-resolution atomic

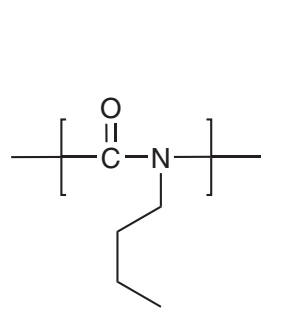

10

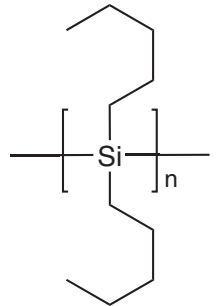

11

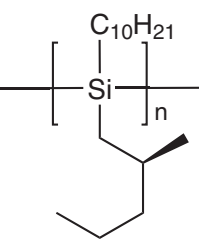

12
$8 / 3$ helix

$7 / 3$ helix force microscopy (AFM), which have been mainly performed in our laboratory, is described.

\section{HELICAL STRUCTURE DETERMINATION BY SINGLE-CRYSTAL X-RAY ANALYSIS OF UNIFORM OLIGOMERS}

The structural determination of helical polymers by XRD at a molecular level is, in general, difficult, because most synthetic helical polymers are composed of a complex repeating unit. However, when the corresponding uniform oligomers can be isolated and crystallized in order to be suitable for the single-crystal X-ray analysis, their helical structures can be determined (Figure 2).

Isotactic polychloral (3) prepared by the helix-sense-selective polymerization of chloral with optically active initiators showed a high optical activity in the film state $\left([\alpha]_{\mathrm{D}}+4000^{\circ}\right)$, and its helical structure was proposed to be a $4 / 1$ helix. ${ }^{18,44}$ However, the polychloral is insoluble in solvents, and further investigations in solutions were difficult. Ute et al. ${ }^{45}$ prepared and isolated a series of isotactic and enantiomerically pure uniform oligomers bearing different end groups (13) by size-exclusion chromatography (SEC) from oligomerization products, which were further resolved into enantiomers by chiral high-performance liquid chromatography. The (-)-pentamer with the $(R, R, R, R, R)$ main-chain configuration was unambiguously determined to be a right-handed $4 / 1$ helical structure on the basis of an X-ray crystallographic analysis. ${ }^{45}$ Isotactic and enantiomerically pure uniform oligomers similar in structure to 13 , but bearing identical end groups (14), have also been isolated. The oligomers have a meso structure, but are chiral, because of their helicity. Their activation energies for the helix-sense inversion $\left(\Delta G^{\neq}\right)$of $\mathbf{1 4}$ were then estimated to be $34.3-82.0 \mathrm{~kJ} \mathrm{~mol}^{-1}$ on the basis of the dynamic nuclear magnetic resonance technique. ${ }^{46}$

The helical structure of the dodecamer of $n$-butyl isocyanate (15) was also determined to be approximately an $8 / 3$ helix. ${ }^{47}$ This helical structure is comparable in structure with the corresponding helical polyisocyanate proposed by the fiber XRD method. ${ }^{38}$ The single-X-ray crystallographic analysis of uniform oligomers has also been used to determine the helical structures of poly(2,3-quinoxaline) $s^{48}$ and $\mathrm{N}$-substituted poly(p-benzamide)s, ${ }^{49}$ which are considered to possess a one-handed helical conformation as evidenced by their intense

Chart 1

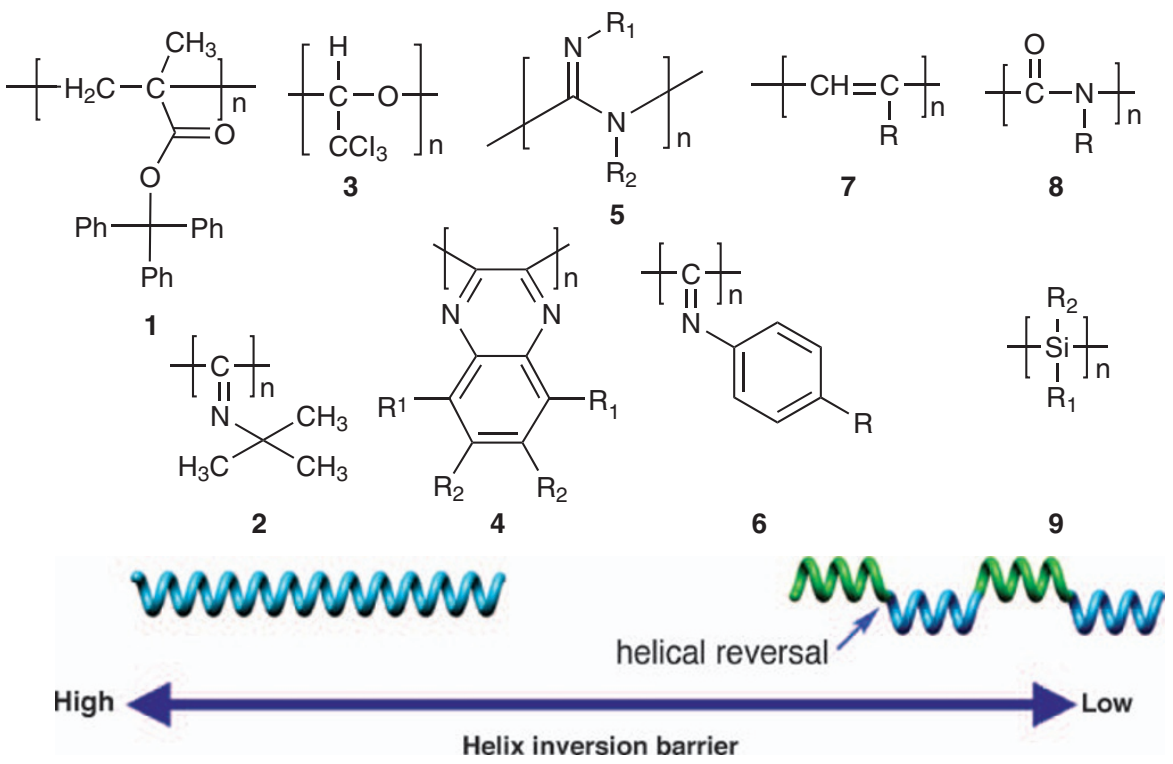

Figure 1 Structures of static and dynamic helical polymers that differ through their helix inversion barriers. 
<smiles>CCCCCCCC(C)(C)[C@@H](C)OC(C)(C)C(C)=O</smiles>

$13(n=2-6)$

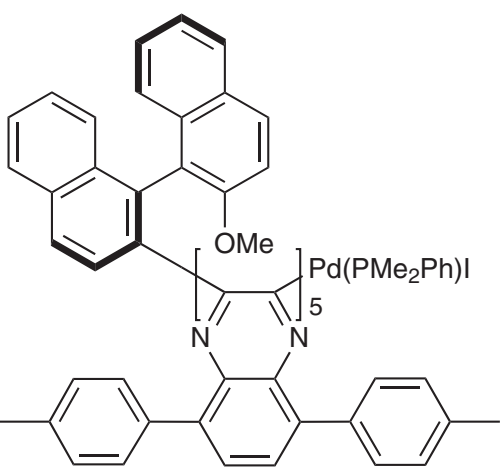

16<smiles>COC(C)(C)[C@@H](OC(C)(C)C)C(C)(C)C</smiles>

$14(n=3-6)$<smiles>CCCCN(C(C)=O)C(=O)C(C)(OCC(F)(F)F)C(C)=O</smiles>

15<smiles>CN(c1ccc(C(=O)C(C)(C)Oc2ccccc2)cc1)C(C)(C)C</smiles>

$17(n=3-5)$

Figure 2 Synthetic uniform helical oligomers, the helical structures of which were determined by single-crystal X-ray crystallographic analyses.
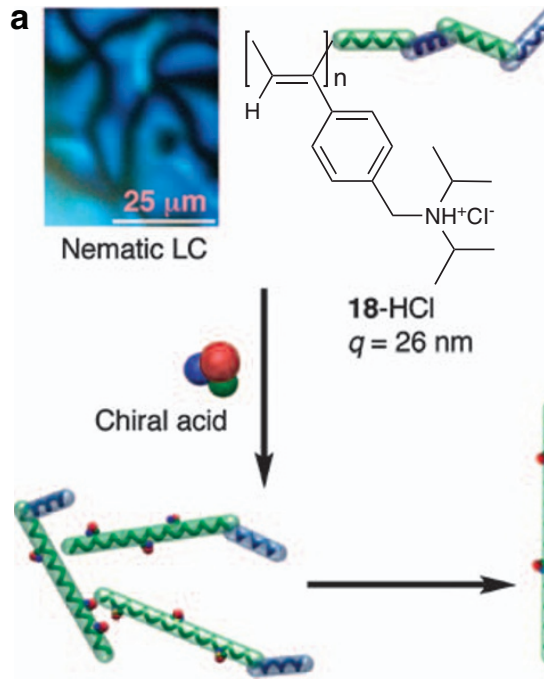

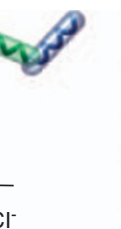

差

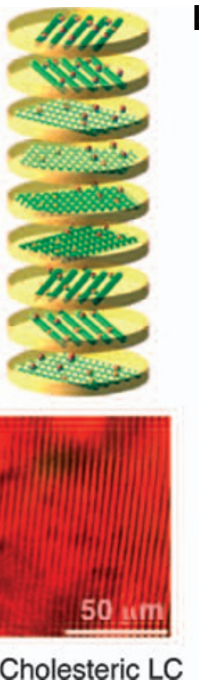

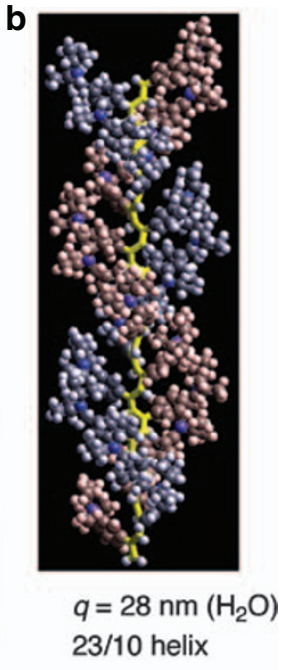

Figure 3 (a) Structure of $18-\mathrm{HCl}$ and polarized optical micrographs (POMs) of nematic and cholesteric liquid crystalline phases. Persistence length (q) before $(26 \mathrm{~nm})$ and after one-handed helicity induction $(28 \mathrm{~nm})$ in $18-\mathrm{HCl}$ is also shown. (b) A $23 / 10$ helical structure of $18-\mathrm{HCl}$ postulated by $\mathrm{X}$-ray diffraction analysis.

Cotton effects. An optically and catalytic active pentamer of a diastereomerically pure oligo(2,3-quinoxaline) (16) was found to have a right-handed $5 / 2$ helix in the solid state. ${ }^{48}$ Tanatani et al. ${ }^{49}$ prepared a series of uniform $N$-methyl-substituted oligo( $p$-benzamide)s (17) by a step-growth oligomerization technique and determined their helical structure to be a $3 / 1$ helix by a single-X-ray crystallographic analysis; this helical structure agrees with that proposed for the corresponding optically active $N$-alkyl substituted poly( $p$-benzamide)s on the basis of their observed and calculated CD spectra.

\section{HELICAL STRUCTURE DETERMINATION OF LIQUID CRYSTALLINE HELICAL POLYMERS BY XRD}

Because of the difficulty in obtaining oriented films suitable for XRD measurements, the helical structures of a limited number of synthetic helical polymers, such as 10-12, have been elucidated by XRD analysis. However, when helical polymers are rigid rods that form a lyotropic or thermotropic LC phase on the basis of their main-chain stiffness, uniaxially oriented films with a regular helical structure over a long distance can be fabricated by physical shearing or under electric or magnetic fields, thus providing useful structural information that defines the main-chain helical structures by XRD. Using this technique, the helical structure of the thermotropic LC $12^{40}$ has been determined to be a $7 / 3$ helix.

Starting with the pioneering research by Aharoni ${ }^{50}$ and Millich $^{51}$ in the late 1970s on the LC formations of polyisocyanates and polyisocyanides, ${ }^{51,52}$ various main-chain LC helical polymers with either static or dynamic helical characteristics have been reported. ${ }^{53}$

In contrast to the stiff helical polyisocyanates and polysilanes, helical polyacetylenes were considered to be too flexible to show an 
LC phase because of their main-chain stiffness. Recently, we found the first example of a helical polyacetylene, the hydrochloride of poly(4(N,N-diisopropylaminomethyl)phenylacetylene) $(18-\mathrm{HCl})$ forming a lyotropic, nematic LC phase in concentrated water, which changed into a cholesteric counterpart with an excess of one helical sense of the polymer induced by a tiny amount of optically active acids (Figure 3). ${ }^{54}$ This LC formation is based on its main-chain stiffness in water as evidenced by its long persistence length $(q)$ before $(26.2 \mathrm{~nm})$ and after the one-handed helicity induction $(28.0 \mathrm{~nm})$ in the polymer. The polyelectrolyte function accompanied by the hydrophobic side groups of this polymer seems to be essential for the LC formation in water, because the neutral polymer showed no LC phase in organic solvents. XRD measurements of the oriented films of nematic and cholesteric LC poly-18-HCls exhibited almost the same diffraction pattern, suggesting that both polymers most likely have the same helical structure in spite of the substantial difference in their helical characteristics: dynamically racemic and one-handed helices, respectively. On the basis of the X-ray analysis of LC samples, the most plausible helical structure of $\mathbf{1 8}-\mathrm{HCl}$ is proposed to be a $23 / 10$ helix (Figure 3)..$^{55}$

An optically active helical poly(phenylacetylene) bearing an L-alanine (L-Ala) residue with a long $n$-decyl chain as pendants (L-19) was found to exhibit an exceptionally long $q$-value of $\sim 130 \mathrm{~nm}$ in nonpolar solvents, such as $\mathrm{CCl}_{4}$, benzene and toluene. Interestingly, its $q$-value dramatically decreased to $19-43 \mathrm{~nm}$ in polar
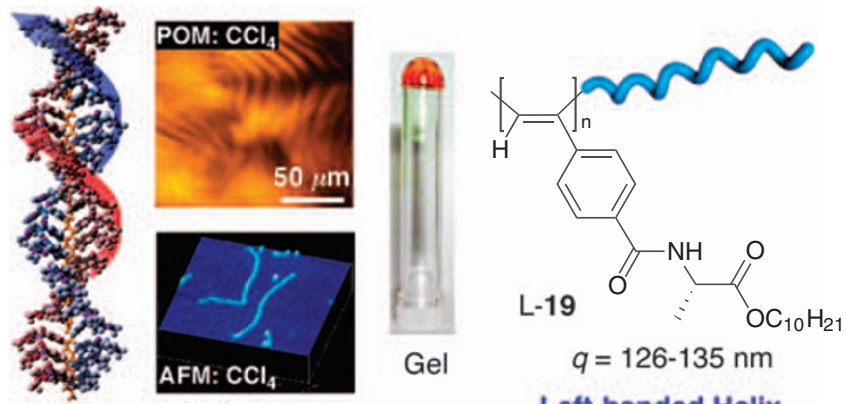

Gel

$q=126-135 \mathrm{~nm}$

Left-handed Helix
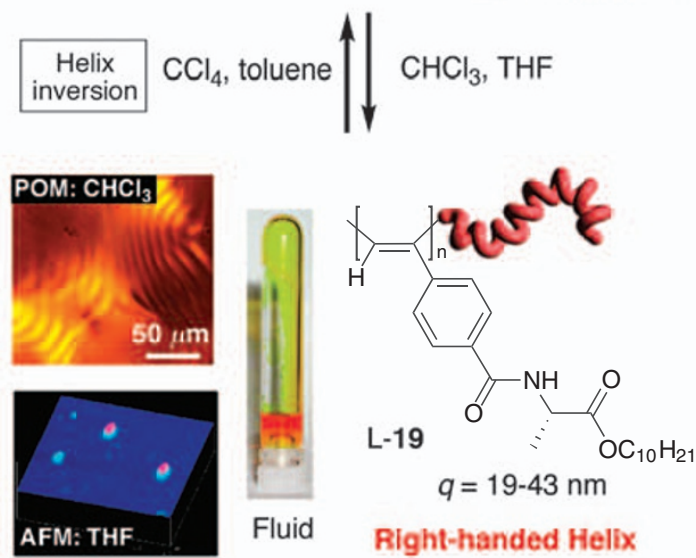

Right-handed Helix

Figure 4 Schematic illustration of the helix inversion of L-19 assisted by solvents with different polarities, leading to diastereomeric helical L-19s with different main-chain stiffness $(q)$. Polarized optical micrographs, AFM height images and the visible differences of L-19 in different solvents are also shown. The helical senses of diastereomeric L-19s are determined by high-resolution atomic force microscopy images of each helical structure on graphite (see Figure 8). Reproduced with permission from Okoshi et al. ${ }^{56}$ Copyright (2006) Wiley-VCH. solvents, such as tetrahydrofuran and chloroform (Figure 4). This significant change in main-chain rigidity is accompanied by an inversion of the main-chain helical sense, resulting from the "on and off" characteristic of the intramolecular hydrogen bonding networks between the pendant amide residues in nonpolar and polar solvents, respectively. ${ }^{56}$ Such a change in the main-chain stiffness of the polymer depending on solvent polarity was also supported by AFM measurements and by the rheological property of the polymer. As expected, the cholesteric LC phases of L-19 with an opposite twist sense to each other derived from an inversion of the macromolecular helicity can be obtained by changing the solvent polarity (Figure 4). ${ }^{56}$ In addition, the macromolecular helicity inversion process can be directly observed by high-resolution AFM measurements (see below). The cholesteric LC L-19 in benzene self-assembled to form a uniaxially oriented film in an electric field because of the large electric dipole moment along the main-chain helical axis. ${ }^{57}$ The polarized optical micrograph, polarized infrared spectroscopy and XRD, as well as molecular modeling, suggest that the L-19 with an opposite helix sense has the same 11/5 helical structure. Moreover, two sets of extended intramolecular hydrogen-bonded arrays of the amide groups at the pendants are helically arranged in a parallel manner, resulting in the generation of the large dipole moment along the helical axis as demonstrated in $\alpha$-helical polypeptides. ${ }^{58}$

A helical poly(phenyl isocyanide) (L-20) (see below) with the same L-Ala pendant groups, such as L-19, also possesses the unprecedented long persistence length of $220 \mathrm{~nm} .{ }^{59}$ This value is, to the best of our knowledge, the highest among all synthetic helical polymers prepared so far and is comparable with those of biological triple-stranded helical polymers, such as collagen $(160-180 \mathrm{~nm})$ and schizophyllan (150-200 nm), and even stiffer than the double-stranded helical DNA $(<60 \mathrm{~nm})$ and xanthan $(120 \mathrm{~nm}) .^{60}$

Previously, we reported that a preferred-handed helicity could be induced in dynamically racemic helical poly(phenylacetylene)s with functional pendant groups. For example, cis-transoidal poly(phenylacetylene)s bearing carboxy (21), ${ }^{24,35,61,62}$ phosphonic (22) ${ }^{63-65}$ and sulfonic acid $(\mathbf{2 3})^{66}$ residues (Figure $5 \mathrm{a}$ ) form a helical conformation with an excess of one-helical sense upon noncovalent complexation with nonracemic amines, such as (R)-1-naphthylethylamine (24), thus showing an induced $\mathrm{CD}$ in the main-chain chromophore regions (Figure 5c). Although the induced CD due to induced preferredhanded helicity immediately disappears when chiral amines are removed, macromolecular helicity can be maintained, that is, 'memorized', after the chiral amines are completely replaced by achiral amines, such as $\mathbf{2 5}$ and 26 (Figure 5b). ${ }^{35,66-68}$ This unique memory effect indicates that the helical conformations of dynamic helical polymers can be locked, transforming into kinetically controlled, static helical polymers, suggesting that either static or dynamic helical polymers with an excess one-handedness will be prepared by the polymerization of analogous monomers bearing different substituents. $^{33}$

Although the helicity memory was stable and lasted for years, the use of achiral amines is essential for memory. Otherwise, chiral memory cannot be retained. However, the sodium salt of helical 27 (27-Na), with an excess single-handed helix induced by $(S)$-phenylalaninol (28), has been found to memorize its induced helicity after a complete removal of the chiral amine in water (Figure 6a). ${ }^{30}$ In sharp contrast to the conformational memory of the induced helical sense of poly(phenylacetylene)s, the helix formation of 27-Na and the subsequent helicity memory were accompanied by a configurational isomerization around the $\mathrm{C}=\mathrm{N}$ double bonds (syn-anti isomerization) (Figure 6b) into uniform configuration on complexation with the 
a

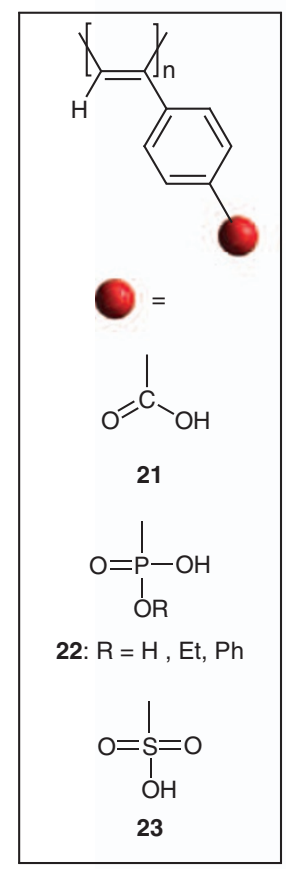

b

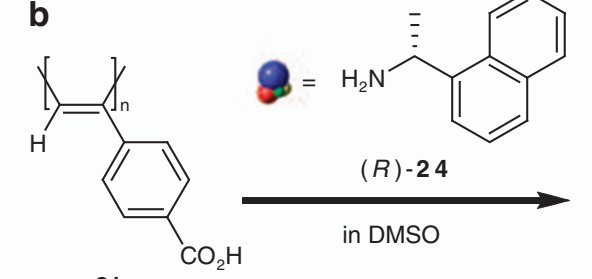

21

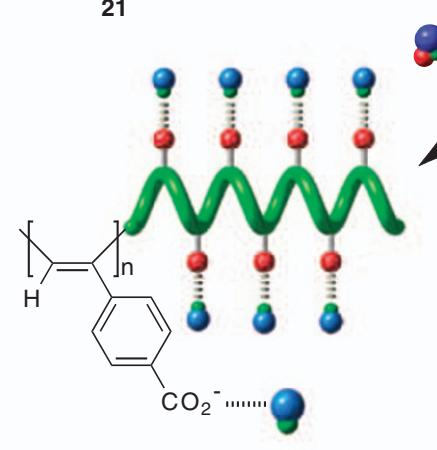

Memory of macromolecular helicity

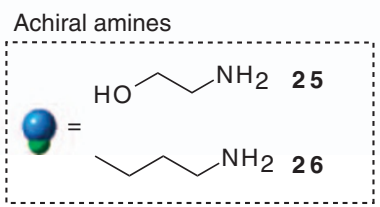

Figure 5 (a) Structures of dynamically racemic helical poly(phenylacetylene)s. (b) Schematic illustration of a preferred-handed helicity induction in $\mathbf{2 1}$ on complexation with $(R)-24$ and subsequent memory of the helicity after replacement with achiral amines $(25,26)$. (c) Circular dichroism spectra of the 21-(R)-24 complex (red line) and the isolated $\mathbf{2 1}$ by size-exclusion chromatography fractionation using a dimethylsulfoxide (DMSO) solution containing an achiral amine $\mathbf{2 5}$ as the mobile phase (blue line) in DMSO.

chiral amine, resulting in the polymer backbone adopting an excess helical sense. ${ }^{69}$ This is remarkable in that a static helical polymer with optical activity can be helix-sense selectively synthesized after polymerization through specific noncovalent chiral interactions.

Taking advantage of this unique and versatile 'static' helicity memory effect, further modifications of side groups with a variety of functional groups of the polyisocyanide are possible without any loss of the macromolecular helicity memory, and the resulting modified polyisocyanides showed cholesteric LC phases (Figure $6 \mathrm{c}$ ) ${ }^{70,71} \mathrm{XRD}$ of the uniaxially oriented film of the methyl ester of helical 27 (h-27-Me) prepared from its cholesteric LC polymer solution after helicity induction and memory suggests that the most plausible helical structure of $\boldsymbol{h}$-27-Me is a 10/3 helix (Figure 6d). ${ }^{69}$ The density functional theory calculations of poly(phenyl isocyanide), a model polymer of $\boldsymbol{h}$-27-Me, showed a 7/2 helix as the most possible helical structure; this calculated helical structure can explain the XRD results. In addition, the persistence length $(q)$ of $\boldsymbol{h}$-27-Me remarkably increases from $59 \mathrm{~nm}$ (27-Me) to $88 \mathrm{~nm}$ once an excess one-handed helicity is induced and memorized in $\boldsymbol{h}-\mathbf{2 7}-\mathbf{M e} .^{69}$

\section{HELICAL SENSE DETERMINATION}

As previously mentioned, it is almost impossible to determine the preferred handedness of helical polymers by conventional XRD. The single-crystal X-ray crystallographic analysis seems to be a reliable and versatile method to unambiguously determine the helical structure at an atomic level including the helical sense, if single crystals of optically active uniform oligomers such as $\mathbf{1 3}$ and $\mathbf{1 6}$ as a model of the corresponding helical polymers are available.

The nonempirical exciton-coupled CD method developed by Harada and Nakanishi ${ }^{72}$ has often been used for predicting the predominant helical sense of synthetic helical polymers, although this method, when applied to helical polymers, involves an uncertainty (Figure 7). Achiral chromophoric dyes, such as porphyrin and diazo moieties, were covalently introduced as pendant groups in the optically active polyisocyanide $29^{73}$ and poly( $N$-propargylamide) $30^{74}$ and polyisocyanide $31,{ }^{75}$ respectively, and their preferred-handed helical senses were proposed on the basis of signs of the split exciton-coupled Cotton effects.

Theoretical calculations of electronic CD, followed by comparison with the observed $\mathrm{CD}$ of certain helical polymers, such as $2^{76}$ and $N$-alkylated optically active poly( $p$-benzamide) (32), ${ }^{49}$ were performed to predict their preferred-handed helical senses in solution. The helical senses of poly( $N$-butynylamide)s having various optically active side chains $(\mathbf{3 3 a}, \mathbf{b})^{77}$ and an optically active poly(phenylacetylene) bearing achiral galvinoxyl pendants (34) prepared by helixsense-selective polymerization ${ }^{78}$ have also been postulated by comparing the observed CD spectra with simulated ones.

The recently developed VCD has significant advantages over the popular electronic CD not only for its sensitivity to chiral nonchromophoric molecules but also for reliable theoretical calculations of its spectrum using the density functional theory available in the Gaussian program. Taking advantage of their available calculation 
a

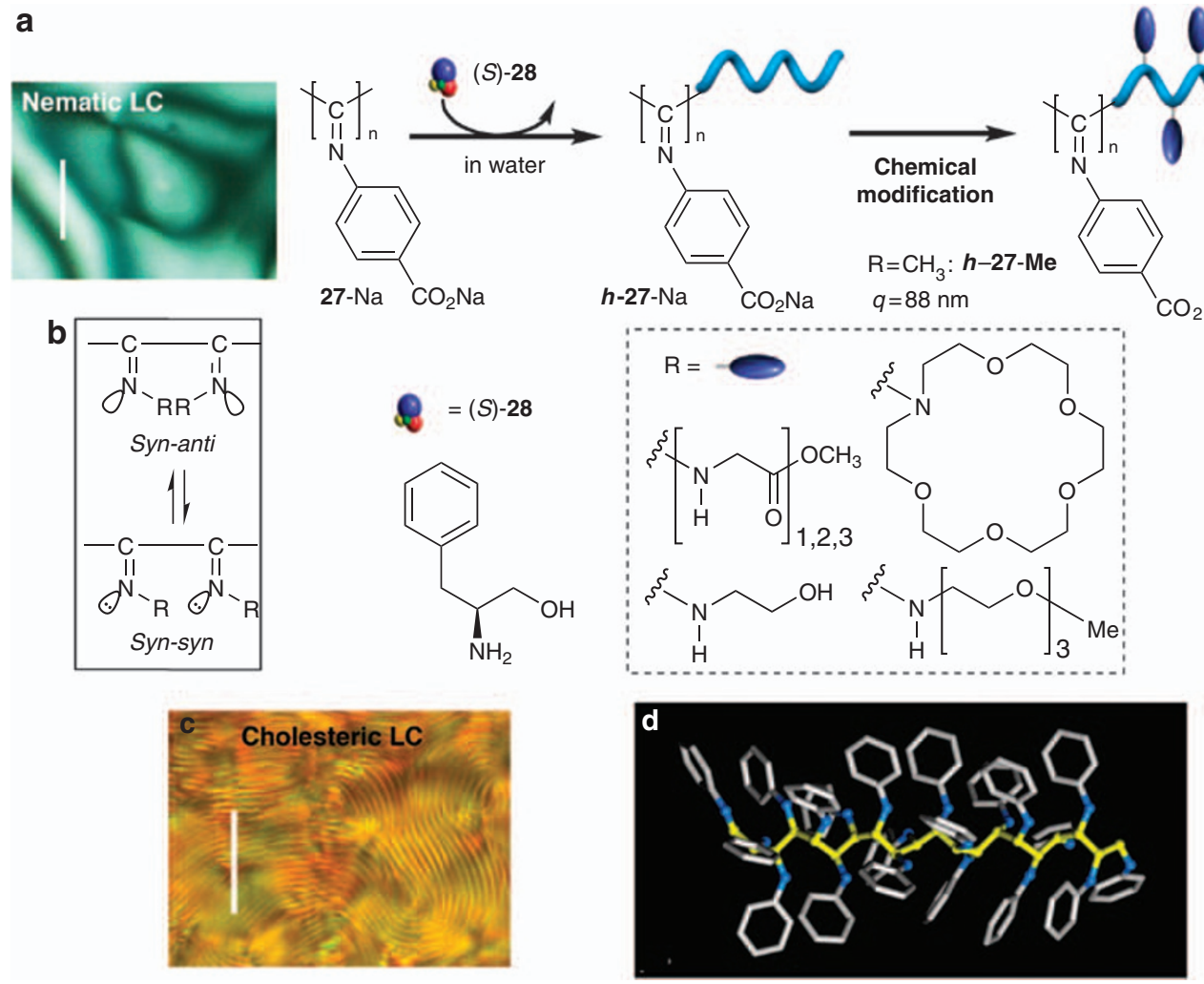

Figure 6 (a) Schematic illustrations of a helicity induction in 27-Na on complexation with (S)-28; memory of the induced helicity after complete removal of (S)-28; and modification of pendants with macromolecular helicity memory. (b) Syn-anti isomerization of the C=N bond. Polarized optical micrographs of nematic (a) and cholesteric (c) liquid crystalline phases and a 10/3 helical structure of $\boldsymbol{h}$-27-Me postulated by X-ray diffraction analysis (d) (hydrogen atoms and methyl ester groups are omitted for clarity) are also shown.

methods, the helical structure of a model oligomer of the optically active polyguanidine (35) prepared by the helix-sense-selective polymerization of the corresponding achiral carbodiimide with a chiral titanium complex was calculated to simulate its VCD spectrum, which has been further used to determine the predominant helical sense of 35 by comparison with the experimental VCD. ${ }^{79}$ In a similar way, using VCD combined with density functional theory calculations, the preferred-handed helical sense of the polyisocyanide with a macromolecular helicity memory $(\boldsymbol{h} \text {-27-Me, Figure } 6)^{69}$ and optically active st-PMMA (see below) ${ }^{80}$ has been determined.

\section{HELICAL STRUCTURE DETERMINATION BY ATOMIC FORCE MICROSCOPY}

The direct observation of helical polymers by scanning probe microscopy is one of the most promising methods for determining helical structures and has been extensively studied. ${ }^{41,42}$ However, scanning probe microscopy observations of helical polymers at the molecular level remain difficult but challenging, even for a large biomolecule such as the double-stranded helix of DNA. ${ }^{81,82}$

L- or D-Ala-Bound poly(phenylacetylene)s (L-19 and D-19) exhibit typical induced CD spectra in the polymer backbone regions that are mirror images of each other, indicating a preferred-handed helical conformation with exactly the same structure, except for the helical sense (Figure 8a). ${ }^{56}$ However, the absolute helical sense of each polymer is unknown, as is the case for other helical polyacetylenes with optical activity.

Recently, we found that helical 19s hierarchically self-assemble on a highly oriented pyrolytic graphite (HOPG) substrate on exposure to benzene vapors. First, flat polyacetylene monolayers spontaneously and epitaxially formed on the basal plane of the graphite because of the strong and epitaxial adsorption of the pendant's alkyl chains on the graphite lattice (Figure 8b), on which helical poly(phenylacetylene)s further self-assembled into chiral two-dimensional (2D) helix bundles with a relatively constant height and controlled helicity (Figure 8c). ${ }^{83}$ The high-resolution AFM image combined with XRD and CD results suggests that 19s possess an 11/5 helix with a helical pitch of $2.3 \mathrm{~nm}$ (Figure 8d), and D-19, showing that the positive first Cotton effect in benzene has a right-handed helical array with respect to pendant arrangements, whereas the main-chain has the opposite, left-handed helical structure. Direct evidence for inversion of the macromolecular helicity of D-19 in different polar and nonpolar solvents has also been visualized for the first time by AFM with molecular resolution on exposure to each solvent vapor. ${ }^{84}$ Regular 2D crystal formation on substrates after annealing in organic solvent vapors may be required for high-resolution $\mathrm{AFM},{ }^{43}$ as the $2 \mathrm{D}$ crystals of polymer chains have the advantage of being sufficiently robust to resist being damaged by the tip during high-resolution AFM measurements; moreover, the flat surface of $2 \mathrm{D}$ crystals allows optimizing AFM settings for high-resolution imaging.

We next applied this procedure to other helical polymers. Specific solvent vapor exposure to helical polymers deposited on HOPG seems to be the key process, through which helical polymers self-assemble into 2D crystals on HOPG with regular helix-bundle structures.

An analogous dynamic helical poly(phenylacetylene) bearing achiral $\alpha$-aminoisobutyric acid (Aib) residues with an $n$-decyl chain (36) no longer has stereogenic centers and is believed to consist of an 


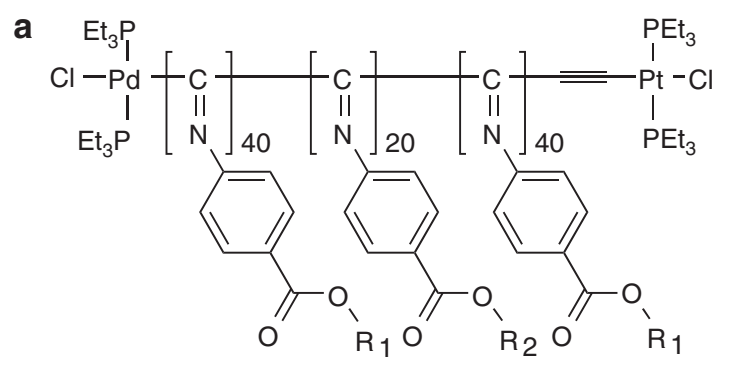

$29 \Delta \varepsilon_{364}:+(P$-helix $)$<smiles>[R]C(=O)OCC(=O)NCC(C)=CCC</smiles>

30

$\Delta \varepsilon_{390}:-(M$-helix $)$ Side-chain arrangement $(P$-helix $)$<smiles>CC(C)=N[C@@H](C)COC(=O)C(C)(C)C</smiles>

31

$$
\Delta \varepsilon_{300}:+(P \text {-helix })
$$

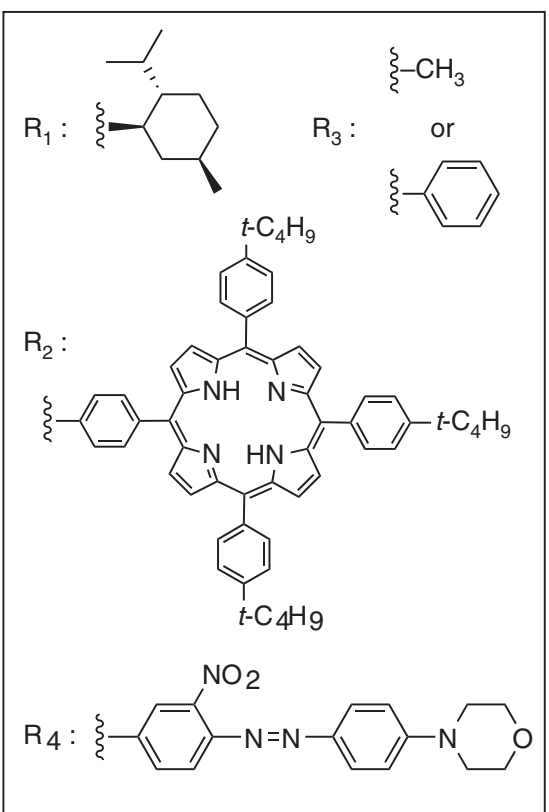<smiles>COCCOCCO[C@@H](C)CN(CC(C)(C)c1ccccc1)c1ccc(C(=O)C(C)(C)c2ccc([N+](=O)[O-])cc2)cc1</smiles>

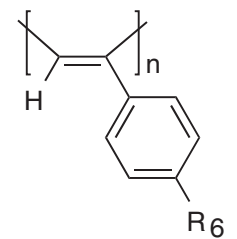

34

$\Delta \varepsilon_{300}:+(P$-helix $)$

$\Delta \varepsilon_{387}:+(P$-helix $)$

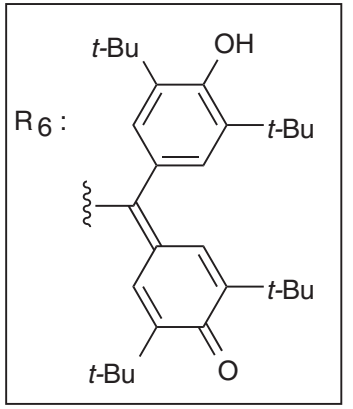

C

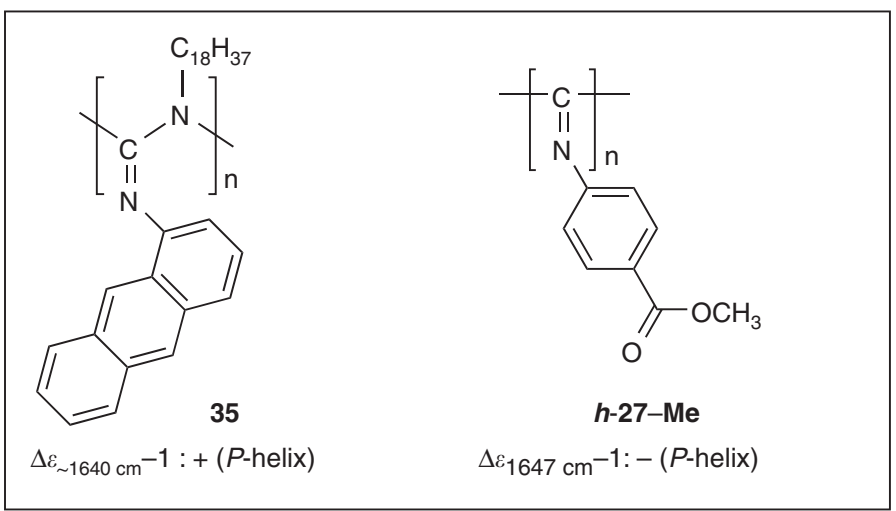

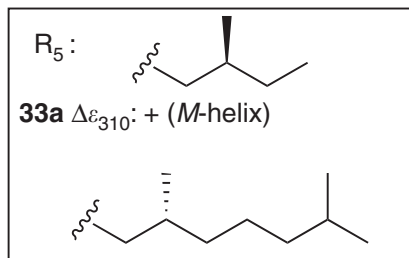

33b $\Delta \varepsilon_{310}:-(P$-helix $)$

Figure 7 Helical senses of synthetic helical polymers determined by the exciton-coupled circular dichroism (CD) method (a), theoretical calculation of CD spectra (b) and density functional theory calculations coupled with vibrational CD measurements (c). Signs of the observed Cotton effects and determined helical senses are also shown. $P$-helix and $M$-helix stand for right- and left-handed helical main-chain structures, respectively.

equal mixture of interconvertible right- and left-handed helical segments separated by helical reversals in solution, as experimentally and theoretically revealed by Green et al. ${ }^{6}$ for polyisocyanates. However, there is no direct evidence because of the extreme difficulty in detecting such dynamic interconvertible helical segments and rarely occurring helical reversals by conventional spectroscopic methods. The high-resolution AFM images of $\mathbf{3 6}$ on HOPG clearly showed enantiomeric right- and left-handed helical block segments separated by helical reversals in individual polymer chains (red and blue colors and white arrows in Figure 9, respectively). ${ }^{85}$ We carefully evaluated the height profiles, and found that there is a gap, along with helical blocks of opposite handedness (yellow arrows), which is different from the helical reversal (white arrows); in this case, two 36 chains align with a distance of $3.4 \mathrm{~nm}$. The AFM images, together with the XRD 

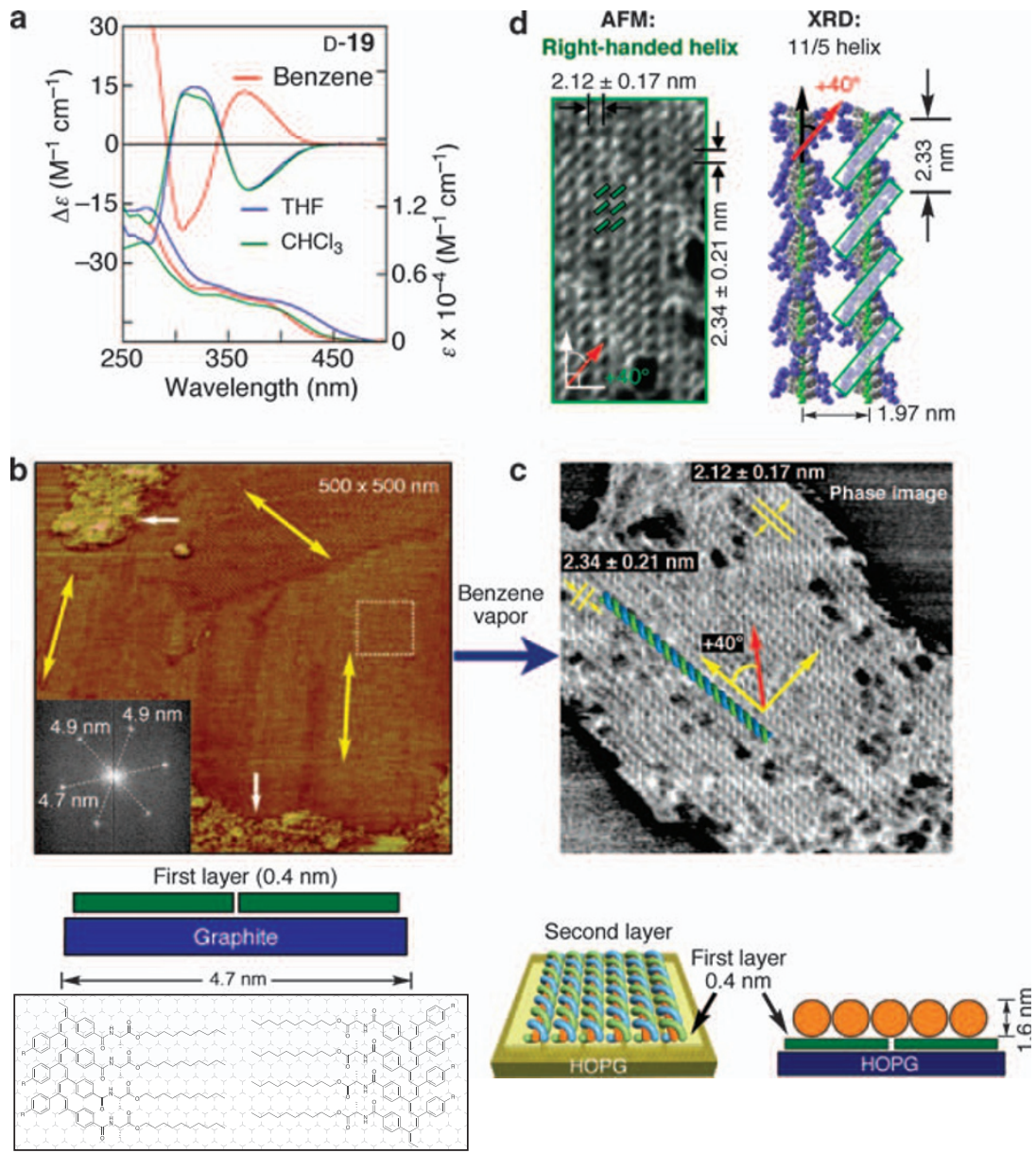

Figure 8 (a) Circular dichroism (CD) and absorption spectra of D-19 in various solvents. (b, c) Atomic force microscopy (AFM) phase images of D-19 before (b) and after (c) benzene vapor exposures on highly oriented pyrolytic graphite (HOPG). Schematic representation of the hierarchical structure of the selfassembled 19 on HOPG is shown (bottom). (d) High-resolution AFM image of D-19 on HOPG and a 15/4 helical structure model constructed on the basis of $\mathrm{X}$-ray diffraction structural analysis. Reproduced with permission from Sakurai et al. ${ }^{85}$ Copyright (2006) Wiley-VCH.

analysis of a one-directionally oriented 36 film obtained from a concentrated nematic LC benzene solution in an electric field, provide an $11 / 5$ helix of 36 with a helical pitch of $2.3 \mathrm{~nm}$. A further statistical analysis of a series of high-resolution AFM images of $\mathbf{3 6}$ covering a wider area revealed that helical reversals along with long helical blocks with the opposite sense appear only once in every 287 monomer units on an average, which corresponds to a $60-\mathrm{nm}$ length in the dynamic helical 36.85

Given the success in visualizing the helical structures of dynamic helical poly(phenylacetylene)s by AFM, the same procedure has been applied to the L-Ala-bound helical polyisocyanide (L-20). The helical structures of polyisocyanides have been postulated to be a $4 / 1$ helix (2), $5,51,86,87$ but the exact helical structures and their absolute helical senses remain unknown except for h-27-Me. ${ }^{69}$

We previously found that diastereomeric right- and left-handed helical polyisocyanides (L-20) were formed by an unprecedented helix-sense-controlled polymerization of an enantiomerically pure phenyl isocyanide bearing the same L-Ala residue with a long $n$-decyl chain as the pendant using an achiral nickel catalyst $\left(\mathrm{NiCl}_{2}\right)$ in different solvents, such as $\mathrm{CCl}_{4}$ and toluene, at different temperatures (Figure 10a). The high-resolution AFM enabled the determination of helical structures, including their helical senses. ${ }^{88}$ L-20a polymerized in $\mathrm{CCl}_{4}$ exhibited a positive first Cotton effect sign
$\left(\Delta \varepsilon_{1 \mathrm{st}}=+8.1\right)$ and self-assembled on HOPG to form slightly irregular 2D helix bundles consisting of major right-handed helical segments with a helical pitch of $1.25 \mathrm{~nm}$, together with minor, but apparently left-handed, helical blocks (Figure 10a, right). These results suggest that L-20a has a predominantly right-handed helical structure, but the helical structure is imperfect. On the other hand, L-20b obtained in toluene at $100{ }^{\circ} \mathrm{C}$ showed an opposite, negative first Cotton effect sign $\left(\Delta \varepsilon_{1 \mathrm{st}}=-11\right)$ after further annealing in toluene at $100^{\circ} \mathrm{C}$ for 6 days; the AFM image clearly revealed an opposite, left-handed helical structure that is predominant in images (Figure 10a, left). Consequently, poly(phenyl isocyanide)s with a positive first Cotton effect sign can be assigned to a right-handed helix. This assignment agrees with that proposed by the exciton-coupled $\mathrm{CD}$ method. ${ }^{73}$ Both diastereomeric right- and left-handed helical L-20a and L-20b further self-assembled into lyotropic cholesteric liquid crystals with an opposite twist sense from each other. On the basis of the X-ray analysis of LC samples, L-20 was found to possess a rigid-rod 15/4 helix; this helical structure is similar in structure to that postulated for a long time for helical polyisocyanides (4/1 helix). ${ }^{5,51,86,87}$

Polymerization of the same L-Ala-bound isocyanide monomer with the $\mu$-ethynediyl $\mathrm{Pt}-\mathrm{Pd}$ catalyst promoted the living polymerization, ${ }^{73}$ which, interestingly, simultaneously produced almost completely right- (L-20c) and left-handed (L-20d) helices with different molecular weights and narrow molecular weight distributions (Figure 10b). 

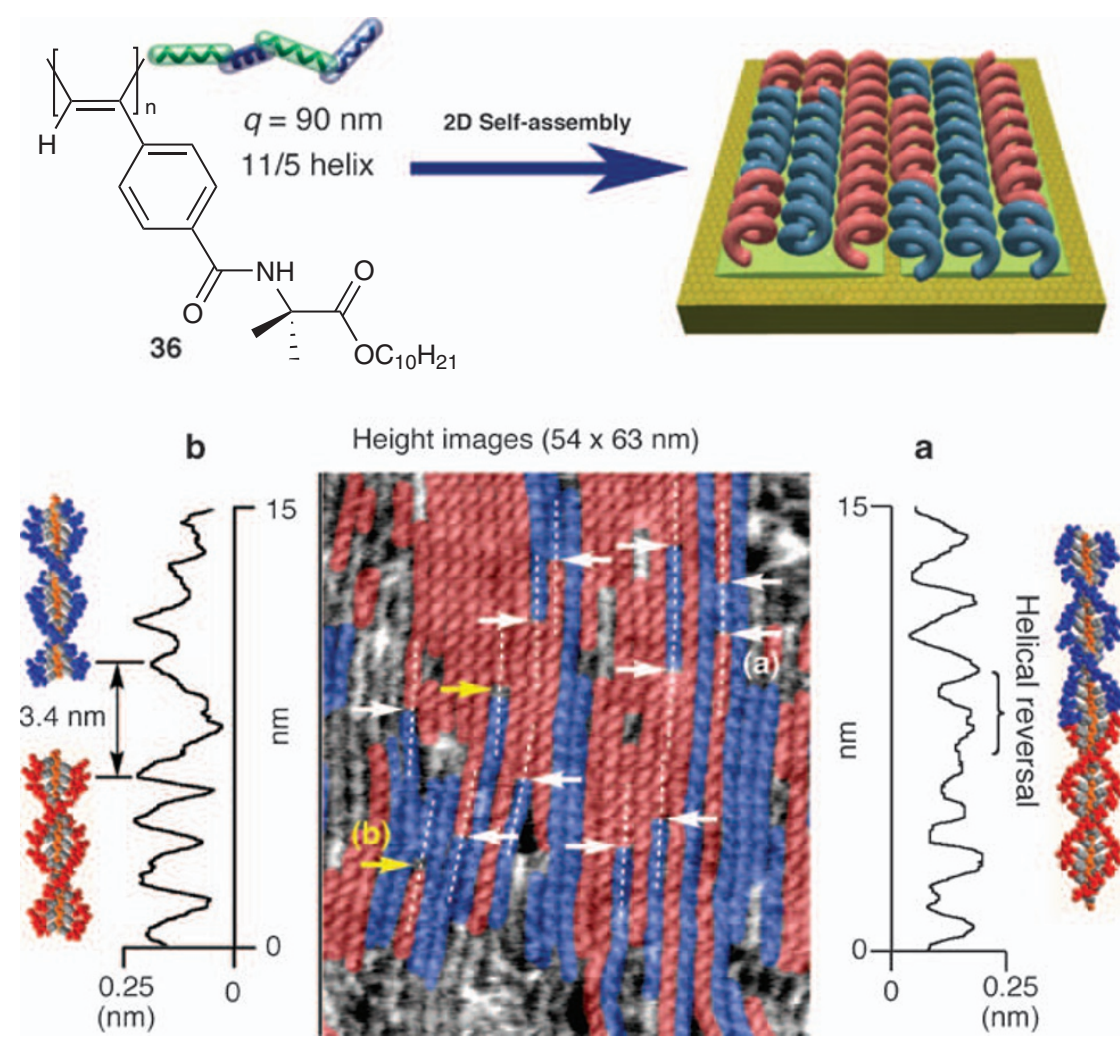

Height images $(54 \times 63 \mathrm{~nm})$

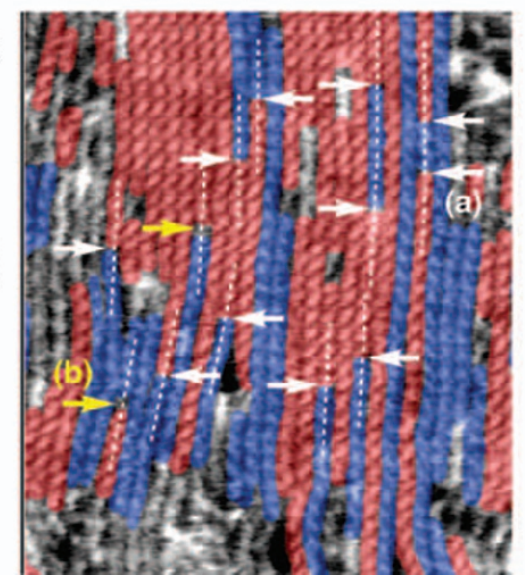

a

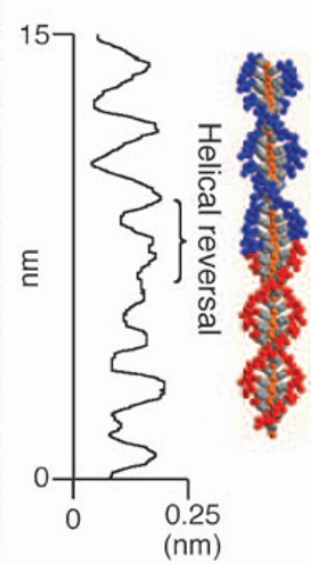

Figure 9 Structure of $\mathbf{3 6}$ and the atomic force microscopy (AFM) height image of two-dimensional self-assembled $\mathbf{3 6}$ consisting of right- (red) and lefthanded (blue) helical segments separated by helical reversals (white arrows) on highly oriented pyrolytic graphite and the cross-section height profiles denoted by white (a) and yellow dashed lines (b). Reproduced with permission from Amabilino et al. ${ }^{87}$ Copyright (2007) Wiley- $\mathrm{VCH}$.

Each single-handed, stiff helical polyisocyanide with a controlled length and handedness can be separated by acetone fractionation and exhibited well-defined 2D- and three-dimensional smectic ordering on HOPG and in the LC state, as directly observed by AFM and revealed by polarized optical micrograph and $\mathrm{XRD}$, respectively (Figure 10b). ${ }^{89}$ On the basis of high-resolution AFM, combined with XRD analysis, it is concluded that both right- and left-handed helical L-20c and L-20d possess a rigid rod 15/4 helix with a helical pitch of $\sim 1.3 \mathrm{~nm}$ assisted by four sets of intramolecular hydrogen bondings. In addition, the helical sense excesses of each polymer can be directly evaluated to be 97 and $99 \%$, respectively, by counting the number of helical senses using high-resolution AFM (Figure 10b). ${ }^{89}$

The isolated right- $(P)$ and left-handed $(M)$ helical L-20c and L-20d maintain their living polymerization activity, and the corresponding L- and D-isocyanide monomers were found to be further block copolymerized in a highly enantiomer-selective manner, whereby narrow molecular weight distributions were maintained. $M$-L-20d preferentially copolymerized the L-monomer over its D-enantiomer by a factor of 6.4-7.7. On the other hand, the D-monomer was preferentially copolymerized over its antipode by a factor of 4.0 , with the $P$-L-20c composed of the same L-monomer units, and the resulting polymer possessed the opposite helix sense. ${ }^{90}$ The highresolution AFM images of block copolymers revealed that the enantiomer-selective block copolymerizations proceeded in an almost perfectly helix-sense-selective manner (Figure 11), as supported by their CD spectra, that is, the helical handedness of macroinitiators L-20c and L-20d determines the overall helical sense of block polyisocyanides, irrespective of the configuration of the monomer units
(L-Ala) of initiators during block copolymerizations. As anticipated, block copolymers maintain their stiffness with a narrow molecular weight distribution and showed lyotropic smectic LC phases. ${ }^{90}$

The present methodology using supramolecular self-assembly into well-defined 2D crystals on substrates provides a useful means of observing the helical structures of other complicated supramolecular helical polymers, such as an artificial double-stranded helical polymer (37) and the poly(methyl methacrylate) (PMMA) stereocomplex.

Double helical 37 is composed of complementary homopolymers bearing $(R)$-amidine and achiral carboxylic acid units that selfassembled to form a complementary double helix with a twist-sense bias through interstrand amidinium-carboxylate salt bridges, as supported by an intense Cotton effect in the main-chain absorption region. The double-stranded helical structure of $\mathbf{3 7}$ was revealed by XRD analysis of uniaxially oriented films and also directly visualized by high-resolution AFM measurements of the 2D crystals of the double-stranded helical polymer adsorbed on HOPG, followed by toluene vapor exposure, which disclosed the helical pitch and its handedness (Figure 12). ${ }^{91}$

It has been reported that complementary strands of isotactic and syndiotactic PMMAs (it- and st-PMMAs) form a unique crystalline supramolecule, the so-called stereocomplex, the structure of which has been proposed on the basis of the XRD analysis of its stretched fiber to be a double-stranded helix composed of a 9/1 it-PMMA helix surrounded by an 18/1 st-PMMA helix with a monomer ratio of $1: 2$, resulting in a complementary double-stranded helix with a helical pitch of $1.84 \mathrm{~nm}$ (Figure 13a). ${ }^{92}$ The AFM image of the stereocomplex (Figure 13c) prepared from a mixed monolayer of it- and st-PMMA chains spread on a water surface upon compression showed helix- 


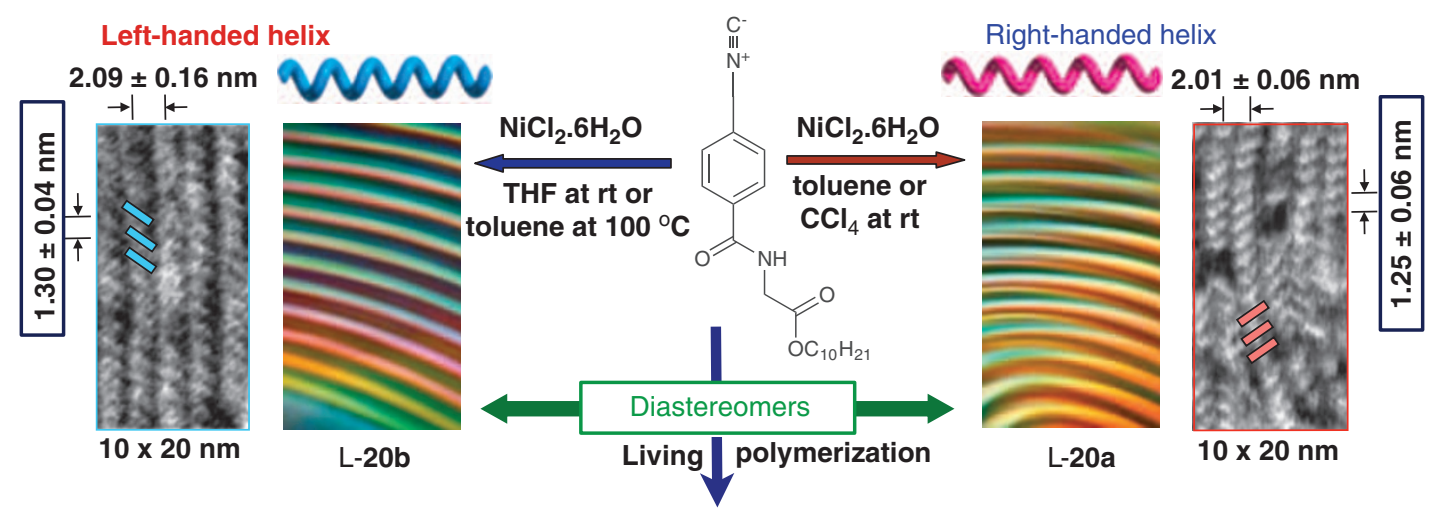

b XRD:

15/4helix
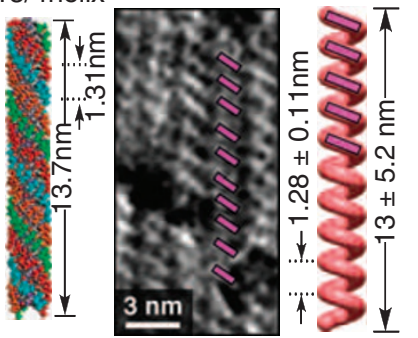

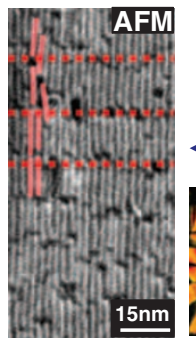

L-20d

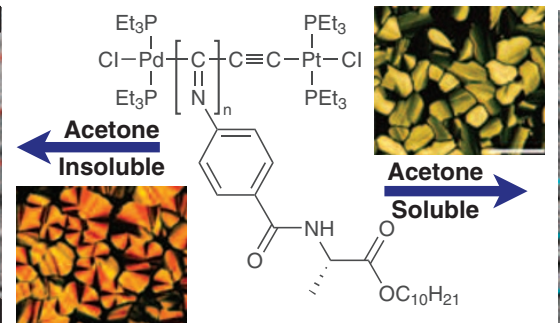

IIt

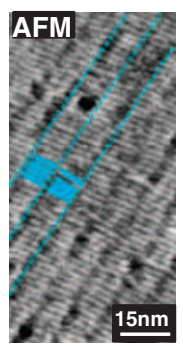

L-20c

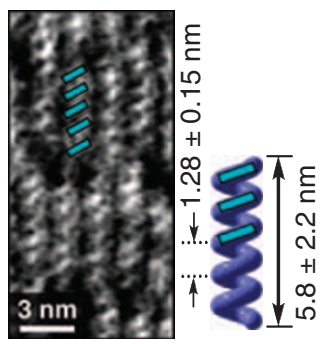

Figure 10 (a) Atomic force microscopy (AFM) phase images of two-dimensional (2D) self-assembled diastereomeric helical L-20a (right) and L-20b (left) obtained from $\mathrm{CCl}_{4}$ and toluene at $100^{\circ} \mathrm{C}$, followed by annealing in toluene at $100{ }^{\circ} \mathrm{C}$ for 6 days on highly oriented pyrolytic graphite (HOPG). Polarized optical micrographs of cholesteric liquid crystalline (LC) phases in chloroform are also shown. Reproduced with permission from Kajitani et al. ${ }^{88}$ Copyright (2006) American Chemical Society. (b) AFM phase images of 2D smectic-assembled L-20c (right) and L-20d (left) on HOPG. Bars and dotted lines indicate the individual polymer chains and 2D smectic layer lines, respectively. High-resolution AFM images on HOPG and polarized optical micrographs of smectic LC phases in chloroform are also shown. Reproduced with permission from Onouchi et al. ${ }^{89}$ Copyright (2008) American Chemical Society.

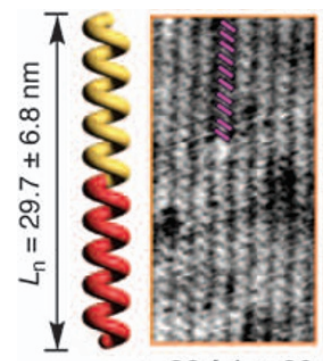

L-20d-b-L-20

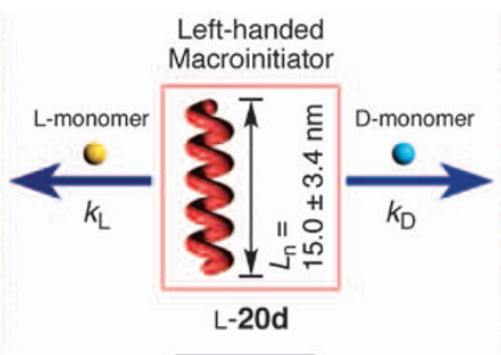

$k_{\mathrm{L}} \gg k_{\mathrm{D}}$

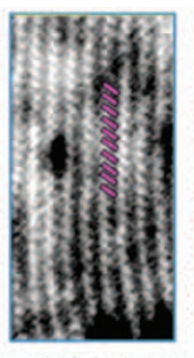

L-20d-b-D-20

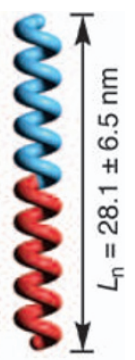

Helix-sense-selective and Enantiomer-selective Polymerization

Figure 11 Schematic illustration of the enantiomer-selective and helix-sense-selective block copolymerization with the left-handed helical L-20d as the macroinitiator, resulting in almost perfect single-handed helical block copolymers with different polymerization rate constants $\left(k_{\mathrm{L}}\right.$ and $\left.k_{\mathrm{D}}\right)$. Atomic force microscopy (AFM) phase images of L-20d-b-L-20 (left) and L-20d-b-D-20 (right) on HOPG are also shown. Scale $=20 \times 40 \mathrm{~nm}$. Reproduced with permission from Wu et al. ${ }^{90}$ Copyright (2009) American Chemical Society.

bundle-like structures, which can be further resolved into individual stripe-patterned chains with a chain-chain lateral spacing of $\sim 2.4 \mathrm{~nm} .{ }^{93}$ In the high-resolution zoomed image (Figure 13d), a number of periodic oblique stripes (green arrows) with a pitch of $0.92 \mathrm{~nm}$ can be observed, which are tilted either clockwise or counterclockwise along the stereocomplex main chain (pink lines) (Figure 13d). These results clearly indicate that the stereocomplex is certainly a supramolecular multistranded helical polymer. Most importantly, the observed helical pitch $(0.92 \mathrm{~nm})$ is exactly equal to half the helical pitch of the proposed double-helix model $(1.84 \mathrm{~nm})$.
On the basis of the ratio $(i t / s t=1 / 2)$ combined with the helical pitch $(0.92 \mathrm{~nm})$ of the stereocomplex observed by AFM, we have proposed a more plausible model for the helical structure of the stereocomplex, that is, a triple-stranded helix (Figure 13b), in which a double-stranded helix composed of two 9/1 it-PMMA helices with a $1.84 \mathrm{~nm}$ helical pitch is surrounded by an 18/1 st-PMMA helix with an observed $0.92 \mathrm{~nm}$ helical pitch. This model satisfies the AFM results, the stoichiometry of $i t$ - and st-PMMAs, as well as the reported helical structures of each component, that is, the it- and st-PMMAs. The double-stranded helical structure was proposed for it-PMMA 

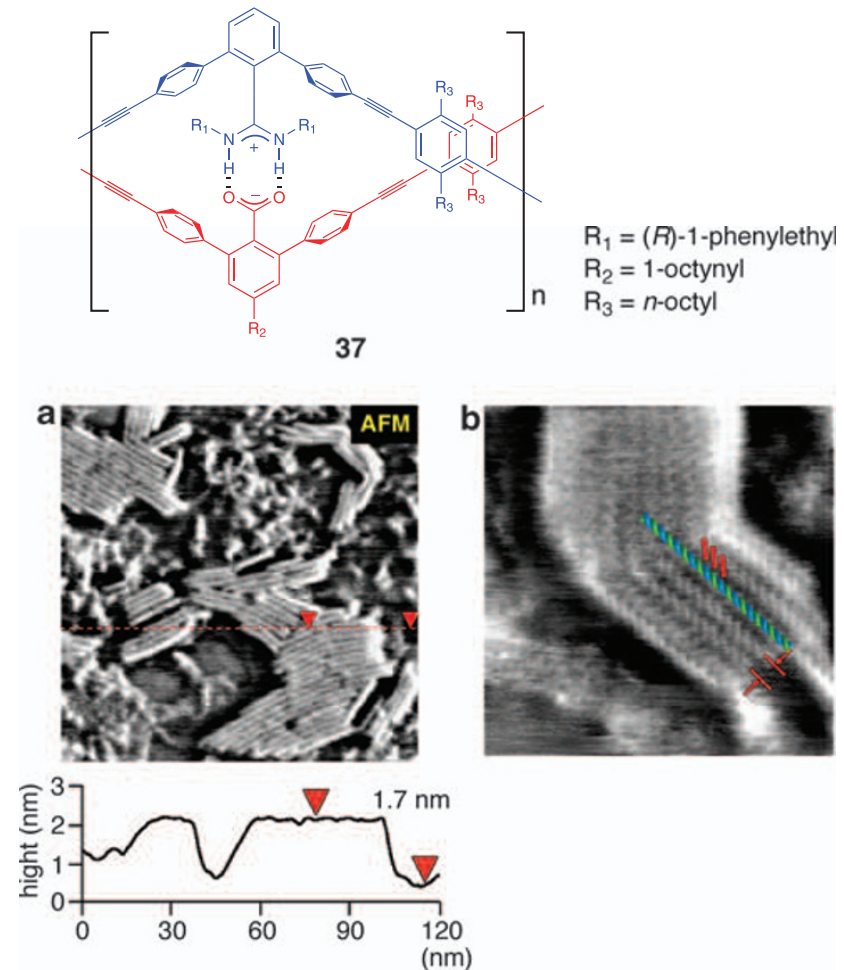

Figure 12 Structure of a complementary double-stranded helical polymer (37). (a) Atomic force microscopy (AFM) phase image of two-dimensional self-assembled 37 on highly oriented pyrolytic graphite with the height profile measured along the dashed line in the image and (b) high-resolution AFM image of 37. Reproduced with permission from Maeda et al. ${ }^{91}$ Copyright (2008) American Chemical Society. on the basis of an XRD analysis ${ }^{94}$ and was further proved by highresolution AFM of an it-PMMA LB film, ${ }^{95}$ whereas st-PMMA is reported to form a crystalline inclusion complex gel with specific organic solvents, such as toluene, resulting in a 74/4 helical structure with a helical pitch of $0.885 \mathrm{~nm}$, in which solvents are encapsulated in the sufficiently large cavity $(\sim 1 \mathrm{~nm})$ of the inner helix. ${ }^{96,97}$ This helical structure is almost identical to that of the st-PMMA component of the triple-stranded helical stereocomplex (Figure 13b). As a consequence, the stereocomplex may not be an intertwined double helix, but may be a supramolecular-assembled inclusion complex composed of an outer st-PMMA helix and an inner it-PMMA double helix. This speculation is supported by the fact that st-PMMA can encapsulate fullerenes and it-PMMA within its helical cavity to form robust and peapod-like inclusion complexes ${ }^{80}$ and a stereocomplex, ${ }^{98}$ respectively.

Recently, we found that a preferred-handed helical st-PMMA can be induced in toluene in the presence of optically active alcohols, such as $(S)$ - or (R)-2-phenylethanol (38), resulting in an optically active gel, which showed a VCD in PMMA infrared regions. On addition of fullerenes, such as $\mathrm{C}_{60}$, helical st-PMMA traps fullerenes within its helical cavity to form an optically active peapod-like inclusion complex (Figure 14). Interestingly, the induced helical structure of the st-PMMA/fullerene complex can be memorized after complete removal of chiral alcohols and the complex exhibited a similar VCD because of the original PMMA in infrared regions, as well as an induced $\mathrm{CD}$ in the encapsulated $\mathrm{C}_{60}$ chromophore regions, although $\mathrm{C}_{60}$ itself is achiral. ${ }^{80}$ Taking advantage of the helicity induction and memory effect in st-PMMA and its inclusion complexation ability, an optically active stereocomplex with a supramolecular helicity memory has been prepared through the inclusion of it-PMMA double helix within the helical cavity of an optically active st-PMMA (Figure 14), ${ }^{98}$

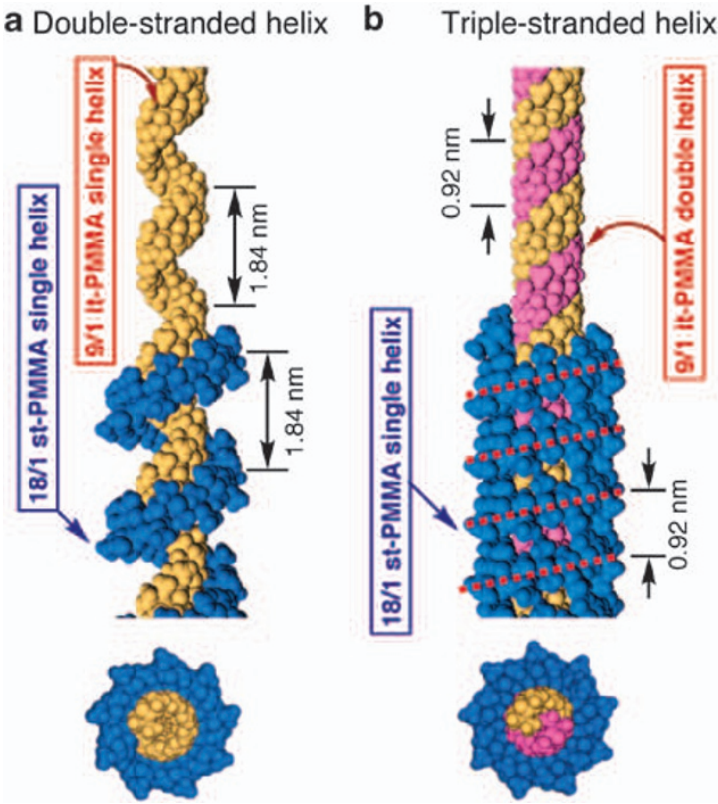

c AFM
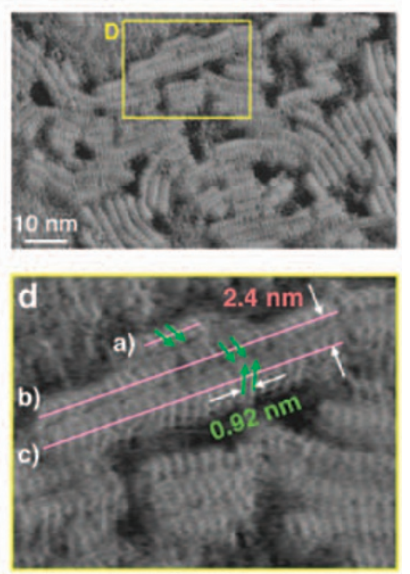

Figure 13 Space-filling models of (a) double-stranded helix and (b) triple-stranded helix models for an it- and st-poly(methyl methacrylate) (PMMA) stereocomplex (it/st=1/2) (top, side view; bottom, through view). The top part of st-PMMA helices is omitted for clarity. (c) Atomic force microscopy phase image of a monolayer of an it- and st-PMMA mixture (it/st=1/2) deposited on mica at $10 \mathrm{mN} \mathrm{m}^{-1}$. (d) Magnified image of the area indicated by the yellow square in (c). Pink lines show the main-chain axes of the stereocomplex; green arrows represent the antipodal oblique pendant helical arrangements with respect to main-chain axes. Reproduced with permission from Kumaki et al. ${ }^{93}$ Copyright (2006) Wiley-VCH. 


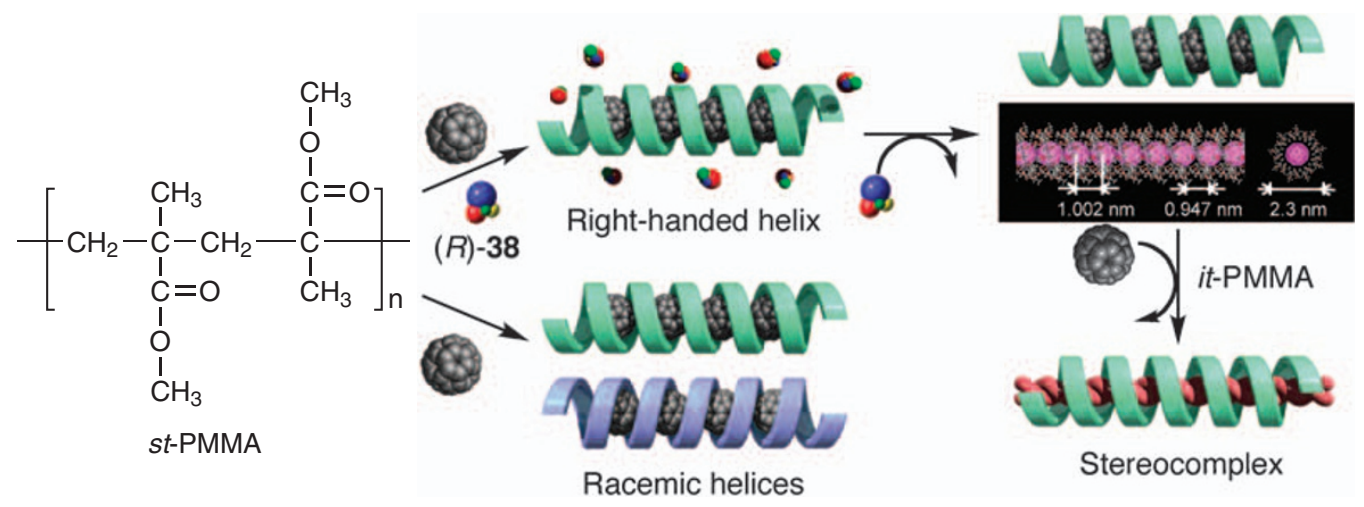

Figure 14 Schematic illustration of a preferred-handed helicity induction in st-poly(methyl methacrylate) (PMMA) in the presence of $C_{60}$ with $(R)$-38; memory of the induced macromolecular helicity after removal of $(R)-\mathbf{3 8}$; and subsequent optically active stereocomplex formation after the addition of it-PMMA, resulting from replacement of the encapsulated $\mathrm{C}_{60}$ molecules by it-PMMA strands.

which also supports the triple-stranded helical structure of the stereocomplex.

\section{CONCLUSIONS}

In this review, the recent progress in the helical structure determination of synthetic helical polymers is mainly described. As described above, a number of helical polymers with numerous variations have been prepared over the past few decades, but limited information on helical structures, in particular, their handedness and helical sense excess, is available. Recent significant developments in spectroscopic and microscopic instruments combined with precise polymerization techniques and computational approaches have made it possible to propose the helical structures of some helical polymers. In particular, taking advantage of a 2D self-assembly technique combined with organic solvent vapor exposures, high-resolution AFM observations of certain helical polymers with a main-chain liquid crystallinity seem to be a powerful method when combined with their XRD analysis to reveal helical structures, including their helical pitch, handedness and helical sense excess at a resolution close to $1 \mathrm{~nm}$. High-resolution AFM is also a powerful alternative method for obtaining key structural information with regard to multistranded supramolecular helical structures, such as a double-stranded helical polymer and multistranded topological PMMA helices. Such structures may be difficult to determine by conventional spectroscopy and XRD measurements.

The structural information obtained from spectroscopic and microscopic measurements, in particular, high-resolution AFM, will be important for further progress in the synthesis of helical polymers with specific structures and functions.

\section{ACKNOWLEDGEMENTS}

We thank to all co-workers for their excellent contributions reported in this review. Financial supports from the Japan Science and Technology Agency and the Grant-in-Aid for Scientific Research (S) from the Japan Society for the Promotion of Science (JSPS) are gratefully appreciated.

1 Okamoto, Y. \& Nakano, T. Asymmetric polymerization. Chem. Rev. 94, 349-372 (1994).

2 Pu, L. The study of chiral conjugated polymers. Acta Polym. 48, 116-141 (1997).

3 Rowan, A. E. \& Nolte, R. J. M. Helical molecular programming. Angew. Chem., Int. Ed. 37, 63-68 (1998).

4 Nakano, T. \& Okamoto, Y. Synthetic helical polymers: conformation and function. Chem. Rev. 101, 4013-4038 (2001).
5 Cornelissen, J. J. L. M., Rowan, A. E., Nolte, R. J. M. \& Sommerdijk, N. A. J. M. Chiral architectures from macromolecular building blocks. Chem. Rev. 101, 4039-4070 (2001).

6 Green, M. M., Peterson, N. C., Sato, T., Teramoto, A., Cook, R. \& Lifson, S. A helical polymer with a cooperative response to chiral information. Science 268, 1860-1866 (1995).

7 Fujiki, M. Optically active polysilylenes: state-of-the-art chiroptical polymers. Macromol. Rapid Commun. 22, 539-563 (2001).

8 Nomura, R., Nakako, H. \& Masuda, T. Design and synthesis of semiflexible substituted polyacetylenes with helical conformation. J. Mol. Catal. A: Chem. 190, 197-205 (2002).

9 Maeda, K. \& Yashima, E. Dynamic helical structures: detection and amplification of chirality. Top. Curr. Chem. 265, 47-88 (2006).

10 Rudick, J. G. \& Percec, V. Induced helical backbone conformations of self-organizable dendronized polymers. Acc. Chem. Res. 41, 1641-1652 (2008).

11 Yashima, E. \& Maeda, K. Chirality-responsive helical polymers. Macromolecules 41, 3-12 (2008).

12 Yashima, E., Maeda, K. \& Furusho, Y. Single- and double-stranded helical polymers: synthesis, structures, and functions. Acc. Chem. Res. 41, 1166-1180 (2008).

13 Pino, P. \& Lorenzi, G. P. Optically active vinyl polymers. II. The optical activity of isotactic and block polymers of optically active $\alpha$-olefins in dilute hydrocarbon solution. J. Am. Chem. Soc. 82, 4745-4747 (1960).

14 Green, M. M. \& Jha, S. K. The road to chiral amplification in polymers originated in Italy. Chirality 9, 424-427 (1997).

15 Nolte, R. J. M., Van Beijnen, A.J.M. \& Drenth, W. Chirality in polyisocyanides. J. Am. Chem. Soc. 96, 5932-5933 (1974).

16 Okamoto, Y., Suzuki, K., Ohta, K., Hatada, K. \& Yuki, H. Optically active poly(triphenylmethyl methacrylate) with one-handed helical conformation. J. Am. Chem. Soc. 101, 4763-4765 (1979).

17 Green, M. M., Andreola, C., Munoz, B., Reidy, M. P. \& Zero, K. Macromolecular stereochemistry: a cooperative deuterium isotope effect leading to a large optical rotation. J. Am. Chem. Soc. 110, 4063-4065 (1988).

18 Corley, L. S. \& Vogl, O. Optically active polychloral. Polym. Bull. 3, 211-217 (1980).

19 Fujiki, M. Ideal exciton spectra in single- and double-screw-sense helical polysilanes. J. Am. Chem. Soc. 116, 6017-6018 (1994).

20 Green, M. M., Reidy, M. P., Johnson, R. J., Darling, G., Oleary, D. J. \& Willson, G. Macromolecular stereochemistry: the out-of-proportion influence of optically active comonomers on the conformational characteristics of polyisocyanates. the sergeants and soldiers experiment. J. Am. Chem. Soc. 111, 6452-6454 (1989).

21 Green, M. M., Garetz, B. A., Munoz, B., Chang, H. P., Hoke, S. \& Cooks, R. G. Majority rules in the copolymerization of mirror-image isomers. J. Am. Chem. Soc. 117, 4181-4182 (1995).

22 Maeda, K. \& Okamoto, Y. Helical structure of oligo- and poly ( $m$-substituted phenyl isocyanate)s bearing an optically active end-group. Pol. J. 30, 100-105 (1998).

23 Inai, Y., Tagawa, K., Takasu, A., Hirabayashi, T., Oshikawa, T. \& Yamashita, M. Induction of one-handed helical screw sense in achiral peptide through the domino effect based on interacting its $n$-terminal amino group with chiral carboxylic acid. J. Am. Chem. Soc. 122, 11731-11732 (2000).

24 Yashima, E., Matsushima, T. \& Okamoto, Y. Poly((4-carboxyphenyl)acetylene) as a probe for chirality assignment of amines by circular dichroism. J. Am. Chem. Soc. 117, 11596-11597 (1995).

25 Suginome, M. \& Ito, Y. Transition metal-mediated polymerization of isocyanides. Adv. Polym. Sci. 17, 77-136 (2004).

26 Ito, Y., Kojima, Y., Murakami, M. \& Suginome, M. Racemization and deracemization of poly(quinoxaline-2,3-diyl)s. Bull. Chem. Soc. Jpn. 70, 2801-2806 (1997).

27 Schlitzer, D. S. \& Novak, B. M. Trapped kinetic states, chiral amplification and molecular chaperoning in synthetic polymers: chiral induction in polyguanidines through ion pair interactions. J. Am. Chem. Soc. 120, 2196-2197 (1998). 
28 Tang, H. Z., Lu, Y. J., Tian, G. L., Capracotta, M. D. \& Novak, B. M. Stable helical polyguanidines: poly $\left\{N\right.$-(1-anthryl)- $N^{\prime}-[(R)$ - and/or (S)-3,7-dimethyloctyl]guanidines. J. Am. Chem. Soc. 126, 3722-3723 (2004).

29 Ishikawa, M., Maeda, K. \& Yashima, E. Macromolecular chirality induction on optically inactive poly(4-carboxyphenyl isocyanide) with chiral amines: a dynamic conformational transition of poly(phenyl isocyanide) derivatives. J. Am. Chem. Soc. 124, 7448-7458 (2002).

30 Ishikawa, M., Maeda, K., Mitsutsuji, Y. \& Yashima, E. An unprecedented memory of macromolecular helicity induced in an achiral polyisocyanide in water. J. Am. Chem. Soc. 126, 732-733 (2004).

31 Lam, J. W. Y. \& Tang, B. Z. Functional polyacetylenes. Acc. Chem. Res. 38, 745-754 (2005).

32 Nomura, R., Fukushima, Y., Nakako, H. \& Masuda, T. Conformational Study of Helical Poly(propiolic esters) in Solution. J. Am. Chem. Soc. 122, 8830-8836 (2000).

33 Aoki, T., Kaneko, T., Maruyama, N., Sumi, A., Takahashi, M., Sato, T. \& Teraguchi, M Helix-sense-selective polymerization of phenylacetylene having two hydroxy groups using a chiral catalytic system. J. Am. Chem. Soc. 125, 6346-6347 (2003).

34 Rudick, J. G. \& Percec, V. Nanomechanical function made possible by suppressing structural transformations of polyarylacetylenes. Macromol. Chem. Phys. 209, 1759-1768 (2008).

35 Yashima, E., Maeda, K. \& Okamoto, Y. Memory of macromolecular helicity assisted by interaction with achiral small molecules. Nature 399, 449-451 (1999).

36 Pauling, L. \& Corey, R. B. The structure of synthetic polypeptides. Proc. Natl. Acad. Sci. USA 37, 241-250 (1951).

37 Watson, J. D. \& Crick, F. H. C. Molecular structure of nucleic acids: a structure for deoxyribose nucleic acid. Nature 171, 737-738 (1953).

38 Shmueli, U., Traub, W. \& Rosenheck, K. Structure of Poly( $N$-butyl isocyanate). J. Polym. Sci., Part A-2: Polym. Phys. 7, 515-524 (1969).

39 Miller, R. D., Farmer, B. L., Fleming, W., Sooriyakumaran, R. \& Rabolt, J. Poly(di- $n-$ pentylsilane). The spectral consequences of a helical conformation in the solid state. J. Am. Chem. Soc. 109, 2509-2510 (1987).

40 Watanabe, J., Kamee, H. \& Fujiki, M. First observation of thermotropic cholesteric liquid crystal in helical polysilane. Pol. J. 33, 495-497 (2001).

41 Schlüter, A. D. \& Rabe, J. P. Dendronized polymers: synthesis, characterization, assembly at interfaces, and manipulation. Angew. Chem., Int. Ed. 39, 864-883 (2000).

42 Sheiko, S. S. \& Moller, M. Visualization of macromolecules a first step to manipulation and controlled response. Chem. Rev. 101, 4099-4124 (2001).

43 Kumaki, J., Sakurai, S.-i. \& Yashima, E. Visualization of synthetic helical polymers by high-resolution atomic force microscopy. Chem. Soc. Rev. 38, 737-746 (2009).

44 Vogl, O., Jaycox, G. D., Kratky, C., Simonsick, W. J. \& Hatada, K. Mapping the genesis of helical structure in polymers of the trihaloacetaldehydes. Acc. Chem. Res. 25, 408-413 (1992).

45 Ute, K., Hirose, K., Kashimoto, H., Nakayama, H., Hatada, K. \& Vogl, O. Helix-inversion equlibrium of isotactic chloral oligomers in solution. Pol. J. 25, 1175-1186 (1993).

46 Ute, K., Hirose, K., Kashimoto, H., Hatada, K. \& Vogl, O. Haloaldehyde polymers. 51. Helix-sense reversal of isotactic chloral oligomers in solution. J. Am. Chem. Soc. 113 6305-6306 (1991).

47 Ute, K., Fukunishi, Y., Niimi, R., Iwakura, T. \& Hatada, K. Helical structure in solution and in the crystalline state of uniform polyisocyanates obtained by supercritical fluid chromatography. Polym. Prep. Jpn. 45, 3284-3285 (1996).

48 Ito, Y., Ohara, T., Shima, R. \& Suginome, M. Highly screw-sense selective polymerization of 1,2-diisocyano-3,6-di-p-tolylbenzene initiated by optically active binaphthylpalladium(ii) complexes. J. Am. Chem. Soc. 118, 9188-9189 (1996).

49 Tanatani, A., Yokoyama, A., Azumaya, I., Takakura, Y., Mitsui, C., Shiro, M., Uchiyama, M, Muranaka, A, Kobayashi, N \& Yokozawa, T Helical structures of N-Alkylated Poly ( $p$ benzamide)s. J. Am. Chem. Soc. 127, 8553-8561 (2005).

50 Aharoni, S. M. Rigid backbone polymers. 2. Polyisocyanates and their liquid-crystal behavior. Macromolecules 12, 94-103 (1979).

51 Millich, F. Rigid rod-random coil transformation, mark-houwink constants, and millich's

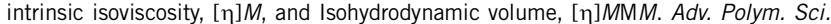
19, 117-141 (1975).

52 Aharoni, S. M. Rigid backbone polymers. I. Polyisocyanides. J. Polym. Sci.: Polym. Phys. Ed. 17, 683-691 (1979).

53 Yashima, E., Maeda, K., lida, H., Furusho, Y. \& Nagai, K. Helical polymers: synthesis, structures and functions. Chem. Rev. 109, 6102-6211 (2009).

54 Maeda, K., Takeyama, Y., Sakajiri, K. \& Yashima, E. Nonracemic dopant-mediated hierarchical amplification of macromolecular helicity in a charged polyacetylene leading to a cholesteric liquid crystal in water. J. Am. Chem. Soc. 126, 16284-16285 (2004).

55 Nagai, K. Sakajiri, K., Maeda, K., Okoshi, K., Sato, T. \& Yashima, E. Hierarchical amplification of macromolecular helicity in a lyotropic liquid crystalline charged Poly(phenylacetylene) by nonracemic dopants in water and its helical structure. Macromolecules 39, 5371-5380 (2006).

56 Okoshi, K., Sakurai, S.-i., Ohsawa, S., Kuniaki, J. \& Yashima, E. Control of main-chain stiffness of a helical poly(phenylacetylene) by switching on and off the intramolecular hydrogen bonding through macromolecular helicity inversion. Angew. Chem., Int. Ed. 45, 8173-8176 (2006).

57 Okoshi, K., Kajitani, T., Nagai, K. \& Yashima, E. Uniaxial orientation of a rodlike helical poly(phenylacetylene) in an electric field. Macromolecules 41, 258-261 (2008).

58 Yen, C.- C., Tokita, M., Park, B., Takezoe, H. \& Watanabe, J. Spontaneous organization of helical polypeptide molecules into polar packing structure. Macromolecules 39 1313-1315 (2006).
59 Okoshi, K., Nagai, K., Kajitani, T., Sakurai, S.-i. \& Yashima, E. Anomalous stiff backbones of helical poly(phenyl isocyanide) derivatives. Macromolecules 41, 7752-7754 (2008).

60 Sato, T. \& Teramoto, A. Concentrated solutions of liquid-crystalline polymers. Adv. Polym. Sci. 126, 85-161 (1996).

61 Yashima, E., Matsushima, T. \& Okamoto, Y. Chirality assignment of amines and amino alcohols based on circular dichroism induced by helix formation of a stereoregular poly((4-carboxyphenyl)acetylene) through acid-base complexation. J. Am. Chem. Soc. $119,6345-6359$ (1997).

62 Goto, H., Zhang, H. Q. \& Yashima, E. Chiral stimuli-responsive gels: helicity induction in poly(phenylacetylene) gels bearing a carboxyl group with chiral amines. J. Am. Chem. Soc. 125, 2516-2523 (2003).

63 Onouchi, H., Maeda, K. \& Yashima, E. A Helical Polyelectrolyte Induced by Specific Interactions with Biomolecules in Water. J. Am. Chem. Soc. 123, 7441-7442 (2001).

64 Onouchi, H., Hasegawa, T., Kashiwagi, D., Ishiguro, H., Maeda, K. \& Yashima, E. Helicity induction in charged poly(phenylacetylene)s bearing various acidic functional groups in water and its mechanism. Macromolecules 38, 8625-8633 (2005).

65 Onouchi, H., Hasegawa, T., Kashiwagi, D., Ishiguro, H., Maeda, K. \& Yashima, E. Chirality Sensing of Various Biomolecules with Helical Poly(phenylacetylene)s Bearing Acidic Functional Groups in Water. J. Polym. Sci., Part A: Polym. Chem. 44, 5039-5048 (2006).

66 Hasegawa, T., Maeda, K., Ishiguro, H. \& Yashima, E. Helicity induction on a poly(phenylacetylene) derivative bearing a sulfonic acid pendant with chiral amines and memory of the macromolecular helicity in dimethyl sulfoxide. Pol. J. 38, 912-919 (2006).

67 Onouchi, H., Kashiwagi, D., Hayashi, K., Maeda, K. \& Yashima, E. Helicity induction on poly(phenylacetylene)s bearing phosphonic acid pendants with chiral amines and memory of the macromolecular helicity assisted by interaction with achiral amines in dimethyl sulfoxide. Macromolecules 37, 5495-5503 (2004).

68 Maeda, K., Morino, K., Okamoto, Y., Sato, T. \& Yashima, E. Mechanism of Helix induction on a stereoregular poly((4-carboxyphenyl)acetylene) with chiral amines and memory of the macromolecular helicity assisted by interaction with achiral amines. J. Am. Chem. Soc. 126, 4329-4342 (2004).

69 Hase, Y., Nagai, K., lida, H., Maeda, K., Ochi, N., Sawabe, K., Sakajiri, K, Okoshi, K \& Yashima, E Mechanism of Helix induction in poly(4-carboxyphenyl isocyanide) with chiral amines and memory of the macromolecular helicity and its helical structures. J. Am. Chem. Soc. 131, 10719-10732 (2009).

70 Hase, Y., Mitsutsuji, Y., Ishikawa, M., Maeda, K., Okoshi, K. \& Yashima, E. Unexpected thermally stable, cholesteric liquid-crystalline helical polyisocyanides with memory of macromolecular helicity. Chem. Asian J. 2, 755-763 (2007).

71 Miyabe, T., Hase, Y., lida, H., Maeda, K. \& Yashima, E. Synthesis of functional poly(phenyl isocyanide)s with macromolecular helicity memory and their use as asymmetric organocatalysts. Chirality 21, 44-50 (2009).

72 Harada, N. \& Nakanishi, K. Circular Dichroic Spectroscopy-Exciton Coupling in Organic Stereochemistry, (University Science Book, Mill Valley, CA, 1983).

73 Takei, F., Hayashi, H., Onitsuka, K., Kobayashi, N. \& Takahashi, S. Helical chiral polyisocyanides possessing porphyrin pendants: determination of helicity by excitoncoupled circular dichroism. Angew. Chem., Int. Ed. 40, 4092-4094 (2001).

74 Tabei, J., Shiotsuki, M., Sanda, F. \& Masuda, T. Determination of helical sense of poly( $N$-propargylamides) by exciton-coupled circular dichroism. Macromolecules $\mathbf{3 8}$, 9448-9454 (2005).

75 Cornelissen, J. J. L. M., Sommerdijk, N. A. J. M. \& Nolte, R. J. M. Determination of the helical sense in alanine based polyisocyanides. Macromol. Chem. Phys. 203, 1625-1630 (2002).

76 Beijnen, A. J. M. V., Nolte, R. J. M., Drenth, W. \& Hezemans, A. M. F. Screw sence of polyisocyanides. Tetrahedron 32, 2017-2019 (1976)

77 Suzuki, Y., Tabei, J., Shiotsuki, M., Inai, Y., Sanda, F. \& Masuda, T. Synthesis and helical structure of poly ( $N$-butynylamide)s having various side chains, where the helix is highly affected by the methyl branch and the lactone moiety. Macromolecules 41, 1086-1093 (2008).

78 Kaneko, T., Umeda, Y., Yamamoto, T., Teraguchi, M. \& Aoki, T. Assignment of helical sense for poly(phenylacetylene) bearing achiral galvinoxyl chromophore synthesized by helix-sense-selective polymerization. Macromolecules 38, 9420-9426 (2005).

79 Tang, H.-Z., Novak, B. M., He, J. \& Polavarapu, P. L. A thermal and solvocontrollable cylindrical nanoshutter based on a single screw-sense helical polyguanidine. Angew. Chem., Int. Ed. 44, 7298-7301 (2005).

80 Kawauchi, T., Kumaki, J., Kitaura, A., Okoshi, K., Kusanagi, H., Kobayashi, K., Sugai, $T$, Shinohara, H \& Yashima, E Encapsulation of fullerenes in a helical PMMA cavity leading to a robust processable complex with a macromolecular helicity memory. Angew. Chem., Int. Ed. 47, 515-519 (2008).

81 Maaloum, M. A Close encounter with DNA. Eur. Biophys. J. 32, 585-587 (2003).

82 Tanaka, H. \& Kawai, T. Partial sequencing of a single DNA molecule with a scanning tunnelling microscope. Nature Nanotech. 4, 518-522 (2009).

83 Sakurai, S.-i., Okoshi, K., Kumaki, J. \& Yashima, E. Two-dimensional hierarchical selfassembly of one-handed helical polymers on graphite. Angew. Chem., Int. Ed. 45, 1245-1248 (2006).

84 Sakurai, S.-i., Okoshi, K., Kumaki, J. \& Yashima, E. Two-dimensional surface chirality control by solvent-induced helicity inversion of a helical polyacetylene on graphite. J. Am. Chem. Soc. 128, 5650-5651 (2006).

85 Sakurai, S.-i., Ohsawa, S., Nagai, K., Okoshi, K., Kumaki, J. \& Yashima, E. Twodimensional helix-bundle formation of a dynamic helical poly(phenylacetylene) with achiral pendant groups on graphite. Angew. Chem., Int. Ed. 46, 7605-7608 (2007). 86 Nolte, R. J. M. Helical poly(isocyanides). Chem. Soc. Rev. 23, 11-19 (1994). 
87 Amabilino, D. B., Serrano, J.-L., Sierra, T. \& Veciana, J. Long-range effects of chirality in aromatic poly(isocyanide)s. J. Polym. Sci., Part A: Polym. Chem. 44, 3161-3174 (2006).

88 Kajitani, T., Okoshi, K., Sakurai, S.-i., Kumaki, J. \& Yashima, E. Helix-sense controlled polymerization of a single phenyl isocyanide enantiomer leading to diastereomeric helical polyisocyanides with opposite helix-sense and cholesteric liquid crystals with opposite twist-sense. J. Am. Chem. Soc. 128, 708-709 (2006).

89 Onouchi, H., Okoshi, K., Kajitani, T., Sakurai, S.-i., Nagai, K., Kumaki, J., Onitsuka, K \& Yashima, E Two- and three-dimensional smectic ordering of single-handed helical polymers. J. Am. Chem. Soc. 130, 229-236 (2008).

90 Wu, Z.-Q., Nagai, K., Banno, M., Okoshi, K., Onitsuka, K. \& Yashima, E. Enantiomerselective and helix-sense-selective living block copolymerization of isocyanide enantiomers initiated by single-handed helical poly(phenyl isocyanide)s. J. Am. Chem. Soc. 131, 6708-6718 (2009).

91 Maeda, T., Furusho, Y., Sakurai, S.- I., Kumaki, J., Okoshi, K. \& Yashima, E. Doublestranded helical polymers consisting of complementary homopolymers. J. Am. Chem. Soc. 130, 7938-7945 (2008).

92 Schomaker, E. \& Challa, G. Complexation of stereoregular poly(methyl methacrylates). 14. the basic structure of the stereocomplex of isotactic and syndiotactic poly(methyl methacrylate). Macromolecules 22, 3337-3341 (1989).
93 Kumaki, J., Kawauchi, T., Okoshi, K., Kusanagi, H. \& Yashima, E. Supramolecular helical structure of the stereocomplex composed of complementary isotactic and syndiotactic poly(methyl methacrylate)s as revealed by atomic force microscopy. Angew. Chem., Int. Ed. 46, 5348-5351 (2007).

94 Kusanagi, H., Tadokoro, H. \& Chatani, Y. Double strand helix of isotactic poly(methyl methacrylate). Macromolecules 9, 531-532 (1976).

95 Kumaki, J., Kawauchi, T. \& Yashima, E. Two-dimensional folded chain crystals of a synthetic polymer in a langmuir-blodgett film. J. Am. Chem. Soc. 127, 5788-5789 (2005).

96 Kusuyama, H., Takase, M., Higashihata, Y., Tseng, H.-T., Chatani, Y. \& Tadokoro, H. Structural change of st-PMMA on drawing, absorption and desorption of solvents. Polymer 23, 1256-1258 (1982).

97 Kusuyama, H., Miyamoto, N., Chatani, Y. \& Tadokoro, H. Crystalline complexes of syndiotactic poly(methyl methacrylate) with some organic solvents. Polym. Commun. 24, 119-122 (1983).

98 Kawauchi, T., Kitaura, A., Kumaki, J., Kusanagi, H. \& Yashima, E. Helix-sensecontrolled synthesis of optically active poly(methyl methacrylate) stereocomplexes. J. Am. Chem. Soc. 130, 11889-11891 (2008).

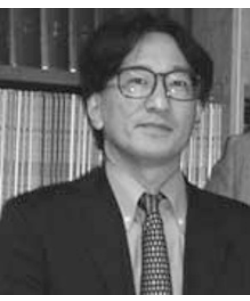

Eiji Yashima received his B.S. (1982), M.S. (1984), and Ph.D. (1988) degrees from Osaka University in the group of Professor Yoshio Okamoto. In 1986, he joined Kagoshima University, working with Professor Mitsuru Akashi as Assistant Professor. After spending one year at UMass with Professor David A Tirrell, he moved to Nagoya University and was promoted to a full Professor in 1998 . He was the project leader of the ERATO Project (JST) on 'Yashima Super-structured Helix' (2002-2007). He received the Wiley Polymer Science Award from the SPSJ in 2000, the Japan IBM Science Award in 2001, Molecular Chirality Award in 2005, Thomson Scientific Research Front Award in 2007, and the Award of the Society of Polymer Science, Japan in 2008. His current research interests are in the design and synthesis of helical molecules, supramolecules, and polymers with novel functions. 